\title{
A permanent Raman lidar station in the Amazon: description, characterization, and first results
}

\author{
H. M. J. Barbosa ${ }^{1}$, B. Barja ${ }^{1,2}$, T. Pauliquevis ${ }^{3}$, D. A. Gouveia ${ }^{1}$, P. Artaxo ${ }^{1}$, G. G. Cirino ${ }^{4}$, R. M. N. Santos ${ }^{5}$, and \\ A. B. Oliveira ${ }^{6}$ \\ ${ }^{1}$ Instituto de Física, Universidade de São Paulo, Rua do Matão, Travessa R, 187. 05508-090, São Paulo, S.P., Brazil \\ ${ }^{2}$ Centro Meteorológico de Camagüey, Instituto de Meteorología de Cuba, Cuba \\ ${ }^{3}$ Depto. de Ciências Exatas e da Terra, UNIFESP, Diadema, S.P., Brazil \\ ${ }^{4}$ Instituto Nacional de Pesquisas da Amazônia, Manaus, A.M., Brazil \\ ${ }^{5}$ Universidade do Estado do Amazonas, Manaus, A.M., Brazil \\ ${ }^{6}$ Instituto Federal de Educação, Ciência e Tecnologia de São Paulo, São Paulo, S.P., Brazil
}

Correspondence to: H. M. J. Barbosa (hbarbosa@if.usp.br)

Received: 31 December 2013 - Published in Atmos. Meas. Tech. Discuss.: 28 January 2014

Revised: 5 May 2014 - Accepted: 9 May 2014 - Published: 18 June 2014

\begin{abstract}
A permanent UV Raman lidar station, designed to perform continuous measurements of aerosols and water vapor and aiming to study and monitor the atmosphere from weather to climatic time scales, became operational in the central Amazon in July 2011. The automated data acquisition and internet monitoring enabled extended hours of daily measurements when compared to a manually operated instrument. This paper gives a technical description of the system, presents its experimental characterization and the algorithms used for obtaining the aerosol optical properties and identifying the cloud layers. Data from one week of measurements during the dry season of 2011 were analyzed as a mean to assess the overall system capability and performance. Both Klett and Raman inversions were successfully applied. A comparison of the aerosol optical depth from the lidar and from a co-located Aerosol Robotic Network (AERONET) sun photometer showed a correlation coefficient of 0.86. By combining nighttime measurements of the aerosol lidar ratio (50-65 sr), back-trajectory calculations and fire spots observed from satellites, we showed that observed particles originated from biomass burning. Cirrus clouds were observed in $60 \%$ of our measurements. Most of the time they were distributed into three layers between 11.5 and $13.4 \mathrm{~km}$ a.g.l. The systematic and long-term measurements being made by this new scientific facility have the potential to significantly improve our understanding of the climatic implications of the anthropogenic changes in aerosol concentrations over the pristine Amazonia.
\end{abstract}

\section{Introduction}

Amazonia is under continuous and constant changes in land use, with important climatic implications (Davidson and Artaxo, 2004). Aerosol concentrations vary from pristine conditions at very low concentrations to heavy loaded conditions, similar to polluted urban areas, following the seasonal cycle of deforestation and biomass burning (Artaxo et al., 2013). These large biomass burning emissions overlap with continuous urban emissions in regions near large metropolitan areas, such as downwind from Manaus (Kuhn et al., 2010). These high concentrations of aerosols and trace gases play an important role in the atmospheric composition, convection, cloud formation and the precipitation regimes (Andreae et al., 2004; Koren et al., 2012), having been even linked to a delay on the wet season onset (Bevan et al., 2009; Butt et al., 2011). To fully understand the climatic implications of the anthropogenic changes in aerosol concentrations over pristine Amazonia, the vertical distribution of the aerosol optical properties need to be known, with long term measurements coupled with ground based and satellite remote sensing. This is critically important to help understanding the interaction of aerosol particles with clouds in tropical regions (Freud et al., 2008; Feingold, 2003). Clouds and aerosols strongly affect the radiation balance (Forster et al., 2007) and it was shown that in Amazonia the cloud cover and aerosol loading has important impacts in the 
radiation balance as well as in carbon uptake by the vegetation (Oliveira et al., 2007; Cirino et al., 2013).

Measurements of the vertical profile of aerosols in the Amazon region started in the dry season of 1985 during the Amazon Boundary Layer Experiment (ABLE2) campaign (Harriss et al., 1988) when an airborne differential absorption lidar (DIAL) was used. Andreae et al. (1988) found smoke and haze layers up to $5 \mathrm{~km}$, frequently distributed in multiple layers. The first campaign to use a standard aerosol lidar was the Smoke, Clouds and Radiation-Brazil (SCARB) campaign (Kaufman et al., 1998). The downward looking lidar onboard the aircraft revealed the spatial structure of plumes with and without cloud activity. Using airborne measurements during the same campaign, Reid et al. (1998) reported a second temperature inversion between 2 and $4 \mathrm{~km}$, corresponding to the top of the convective layer, trapping the aerosol layer below it. These results revealed a very complex aerosol vertical structure, with implications in the vertical temperature profile.

Some intensive campaigns relied only on airborne in situ instrumentation for assessing the vertical distribution. For instance, during the dry season of 1992, the Transport and Atmospheric Chemistry Experiment-A (Pereira et al., 1996, TRACE-A) campaign performed six flights for measuring the vertical distribution of biomass burning aerosol. The maximum particle mass concentration of about $15000 \mathrm{~cm}^{-3}$ was found near the temperature inversions around $2.5 \mathrm{~km}$. The Cooperative Large Scale Biosphere-Atmosphere (LBA) Regional Experiment (CLAIRE-98) was the first large campaign during the wet season and measurements were taken with a Brazilian Bandeirante plane over the northern Amazon (Formenti et al., 2001). Two days with strong impact of Saharan dust aerosols were identified in a layer extending from the ground to $3.5 \mathrm{~km}$. Some measurements showed an unexpected increase of trace gas concentrations above $10 \mathrm{~km}$. Employing back trajectories calculations, Andreae et al. (2001) concluded that it originated from savanna fires further downwind that were vertically transported by deep convection and brought equatorward by the upper level circulation. Analysis of aerosol size distributions indicated a possible formation of new particles near the detrainment zone of deep convection (Krejci et al., 2003). Latter, the LBA - Smoke, Aerosols, Clouds, Rainfall and Climate (LBASMOCC) campaign found aerosol scattering increasing with altitude by a factor of 2 to 10, which Chand et al. (2006) attributed to the aging of biomass burning particles. From the same experiment, Guyon et al. (2005) showed that as aerosols are transported above the mixing layer the particle number concentration was reduced by only $20 \%$ while the particle size increased. The authors concluded that the transport by non-precipitating shallow clouds was the most important.

The first relatively long-term ground-based lidar observations in the central Amazon took place during the European Integrated Project on Aerosol, Cloud, Climate, Air Quality
Interactions, (EUCAARI, Kulmala et al., 2011), and the Amazonian Aerosol Characterization Experiment (AMAZE08, Martin et al., 2010). From 10 months of observations in 2008, Baars (2011) analyzed 60 wet and 55 dry season days where meteorological and instrumental conditions were optimal. In a more detailed study, Baars et al. (2011) identified both the transport of Saharan dust and/or biomass burning from Africa in $32 \%$ of their wet season observations, thus confirming previous findings of sporadic intrusions of Saharan dust (Talbot et al., 1990; Formenti et al., 2001) and African fires (Kaufman et al., 2005). The authors were able to quantify the contribution and compute the aerosol optical depth (AOD) for smoke and biomass burning aerosols separately, showing that at least for half of these cases African biomass burning dominated the total AOD. The long-range transport occurred below $3.5 \mathrm{~km}$, while in clean conditions the biogenic aerosols were found to be trapped below $2 \mathrm{~km}$. Baars et al. (2012) showed that column AOD, the maximum extinction and backscatter coefficients during the dry season were about three times higher than during the wet season of 2008. Moreover, an analysis of biomass burning plumes heights indicated that the convective mixing by pyro or deep cumulus was determinant for the vertical distribution of aerosols, indicating the important role of aerosol-cloud interactions in tropical regions (Boucher et al., 2013).

As can be noted from the previous discussion, the vertical distribution of the aerosol optical properties in the Amazon is known only during limited time periods, therefore not allowing for a climatological perspective as well as a clear picture of the strong seasonality characteristic of tropical regions. To overcome this lack of knowledge, a permanent UV Raman lidar station was implemented in the central Amazon in mid2011 aiming to study and monitor the vertical distribution of aerosols and water vapor, and also to study the aerosol-clouds interactions. This paper reports on this new instrument, its first measurements of clouds and aerosols taken during a week of intensive operational period in September 2011. The water vapor measurement methods and results will be presented in an upcoming publication. Section 2 gives the system description and discusses its characterization and analysis algorithm is presented in Sect. 3. Section 4 presents the first results. Finally, in Sect. 5 conclusions and future work are discussed.

\section{Instrument description and performance}

The site is located up-wind from the city of Manaus-AM, Brazil, inside the campus of Embrapa Amazônia Ocidental at $2.89^{\circ} \mathrm{S} 59.97^{\circ} \mathrm{W}$ and $100 \mathrm{~m}$ altitude. This new experimental site was implemented in 2011 and planned to run continuously during the next years applying a synergy of different instruments to help understanding the interactions and feedback mechanisms between humidity, convection, clouds and aerosols. It was initially implemented by the FAPESP 
(Fundação de Amparo a Pesquisa do Estado de São Paulo) project - Direct and indirect effects of aerosols on climate in Amazonia and Pantanal (Artaxo et al., 2013), but also received contribution from FAPESP project - Cloud processes of the main precipitation systems in Brazil: a contribution to cloud resolving modeling and to the GPM = Global Precipitation Measurement Mission (Machado et al., 2014), the project Amazonian Dense GNSS = Global Navigation Satellite System Meteorological Network (Adams et al., 2011) and the Max Planck Institute in Hamburg. Instruments available are UV Raman lidar, ceilometer, sunphotometer, multifilter radiometer, nephelometer, aethalometer, weather station, disdrometer, vertical pointing rain radar and water vapor column using GNSS. This paper focuses mostly on the characterization and first results obtained with the Raman lidar, further described below. Data from collocated and nearby operational soundings are also used. For the validation of the optical properties derived from the lidar measurements, aerosol optical depth from the collocated Aerosol Robotic Network (AERONET) station (Holben et al., 1998) is used.

The lidar system LR-102-U-400/HP was manufactured by Raymetrics Advanced Lidar Systems, in Greece. It uses a Quantel CFR-400 Nd-YAG laser at $355 \mathrm{~nm}$ with $95 \mathrm{~mJ}$ per pulse and $10 \mathrm{~Hz}$ repetition rate. The beam is expanded by a factor of 4 and final laser divergence is $0.36 \mathrm{mrad}$. The optical system is bi-axial with a $300 \mathrm{~mm}$ separation between the Cassegrain telescope and the laser axis, which is tilted by $0.28 \mathrm{mrad}$ towards the first. The primary mirror of the telescope has $400 \mathrm{~mm}$ diameter, while the secondary has $90 \mathrm{~mm}$. Focal length is $4000 \mathrm{~mm}$ resulting in a f/10 system. The diameter of the iris used at the focal plane can be changed, allowing the telescope field of view to be adjusted between 0.25 and $3 \mathrm{mrad}$. The incoming light passing through the iris goes into the detection box. There, a pair of convergent lenses collimates the light into a beam with $8 \mathrm{~mm}$ diameter. Three dichroic beam splitters separate the elastic back scattered signal and the inelastic signals due to the Raman crosssection of $\mathrm{N}_{2}(387 \mathrm{~nm})$ and $\mathrm{H}_{2} \mathrm{O}(408 \mathrm{~nm})$. Interference filters with $1 \mathrm{~nm}$ FWHM before each photomultiplier tube reduce the background noise. For the elastic channel, a neutral density filter is used to attenuate the signal and avoid saturation. Light signals are measured with Hamamatsu R9880U110 photomultiplier tubes (PMT).

Data acquisition is based on the Licel transient recorder model TR-20-160 manufactured by Lidar Computing and Electronics (Licel) $\mathrm{GmbH}$. This integrated optical detection system combines analog (AN) and single photon counting (PC) measurements. The 12-bit analog to digital converter (ADC) processes data from the 355 and $387 \mathrm{~nm}$ signals at $20 \mathrm{MHz}$, yielding a raw resolution of $7.5 \mathrm{~m}$. The ADC scale can be set to 20,100 or $500 \mathrm{mV}$, corresponding to a resolution of $0.005,0.024$ and $0.122 \mathrm{mV}$. These ADC have a linear response for signals above 5 times the resolution and below $50 \%$ of the scale. Photon counting is performed at $250 \mathrm{MHz}$ for the 355,387 , and $408 \mathrm{~nm}$ signals and no
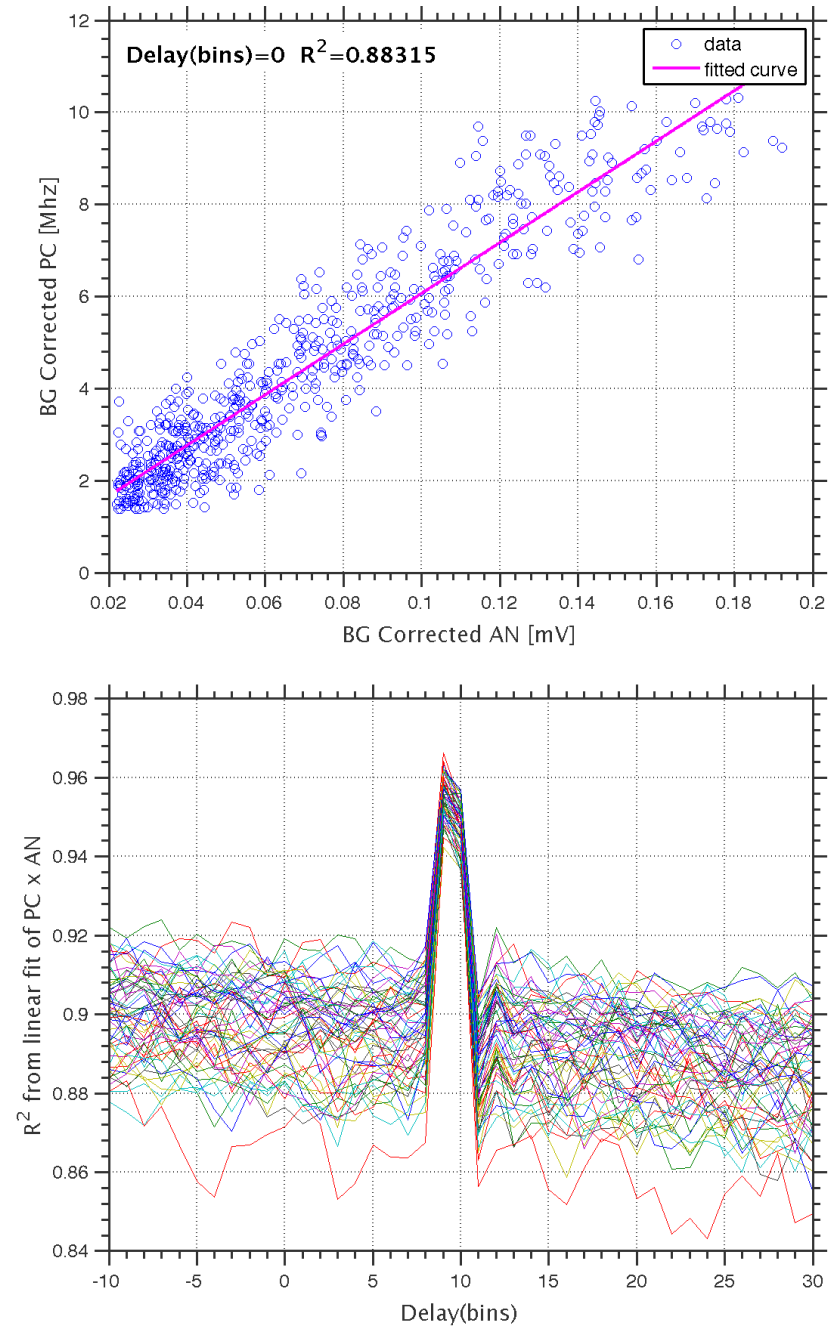

Figure 1. Sample fitting between the $\mathrm{PC}$ and channel in the linear region (top) and lag-correlation as a function of the lag for all profiles in one-hour of measurements (bottom) are shown.

dead time correction is necessary for values below $15 \mathrm{MHz}$. The simultaneous measurement in analog and photon count modes allows extending the dynamical range of the instrument, making it possible to measure from $\sim 500 \mathrm{~m}$ to above $15 \mathrm{~km}$ with a single telescope.

Due to the analog to digital converter bandwidth and pipelining, a time delay between the AN and PC is expected. For measuring this delay, 60 profiles with 600 shoots each were used. A linear regression between $\mathrm{AN}$ and $\mathrm{PC}$ data were performed over the linear response region. The left panel of Fig. 1 shows one of such regressions, for a single profile and no delay. The right panel shows, for all 60 profiles, the $R^{2}$ coefficient from the fitting as a function of the time delay, from -10 up to 30 bins. The result indicates a time lag between 9 and 10 bins, i.e., of about $0.475 \mu$ s. For simplicity, all $\mathrm{AN}$ channels are corrected for a 10 bin delay $(0.5 \mu \mathrm{s})$. 
For extending the linear response of the PC channels above $15 \mathrm{MHz}$, the measured photon count readings are corrected for pulse pileup effects. For non-paralyzable systems (Whiteman et al., 1992; Knoll, 2010) the correction is

$C(z, t, \tau)=N(z, t) /(1-N(z, t) \tau)$,

where $N(z, t)$ and $C(z, t, \tau)$ are the uncorrected and corrected photon count rates at time $t$ and range $z$, respectively, and $\tau$ is the dead time. The dead time is estimated as in Newsom et al. (2009) by varying $\tau$ during successive gluing procedures (Whiteman et al., 2006). In this procedure, because $\mathrm{AN}$ and corrected $\mathrm{PC}$ are linear, the true count rate is approximated by $\hat{C}=a \mathrm{AN}+b$, where $a(t)$ and $b(t)$ are the gluing coefficients, and $\tau$ is chosen to minimize the residual:

$J(t, \tau)=\frac{1}{n} \sum_{i=1}^{n}\left(\frac{C\left(z_{i}, t, \tau\right)-\hat{C}\left(z_{i}, t\right)}{\sigma_{i}}\right)^{2}$,

where $\sigma_{i}$ is the standard deviation of $C$, calculated as the square root of $C$ and $n$ is the number of points used in the linear fit for the determination of $\hat{C}$. Figure 2 shows an example $J(t, \tau)$ obtained from a single profile for $\tau$ between 1 and $7 \mathrm{~ns}$. This was repeated for 580 one-min averaged nighttime profiles for the elastic and nitrogen Raman channels. $\tau_{\min }$ followed a gaussian distribution, with $\tau_{\mathrm{pmt} \# 1}=4.14 \pm 0.11 \mathrm{~ns}$ and $\tau_{\mathrm{pmt} \# 2}=3.98 \pm 0.10 \mathrm{~ns}$, respectively, both in close agreement with manufacturer specification of $4 \mathrm{~ns}$. Therefore, the default value is assumed to be correct for the photon count for the water vapor channel. Figure 3 shows a 20 min average PC example signal before and after the dead time correction. The dashed lines are the percentage difference to the glued signal, assumed to be the true count rate. The difference is negligible below $50 \mathrm{MHz}$. However, it reaches $5 \%$ at only $125 \mathrm{MHz}$, showing that it is indeed necessary to combine the AN and PC data to increase the dynamical range of the detection system.

Electronic noise was evaluated by acquiring data during nighttime with the telescope covered. The first and second AN channels showed a constant background noise of about $1.583 \pm 0.018 \mathrm{mV}$ and $2.012 \pm 0.020 \mathrm{mV}$, respectively, over the range of interest $(<30 \mathrm{~km})$ for profiles with 100 shoots. For these same profiles, the photon count channels showed less than 1 random count per profile within the same range. In general, good signal to noise ratio $(S / N>5)$ can be found above $15 \mathrm{~km}$ depending on the atmospheric conditions. The $\mathrm{N}_{2}$ channel, $1 \mathrm{~min}$ average signals have good $S / N$ up to $15 \mathrm{~km}$ but only during nighttime. For the $\mathrm{H}_{2} \mathrm{O}$ channel, 1 min average signals have good $S / N$ only up to $6 \mathrm{~km}$ during nighttime.

The system is fully automated and includes a clockcontrolled external shutter to cover the telescope field of view from direct sunlight exposure between 11:00 a.m. and 02:00 p.m. local time (UTC-4). As a backup system,
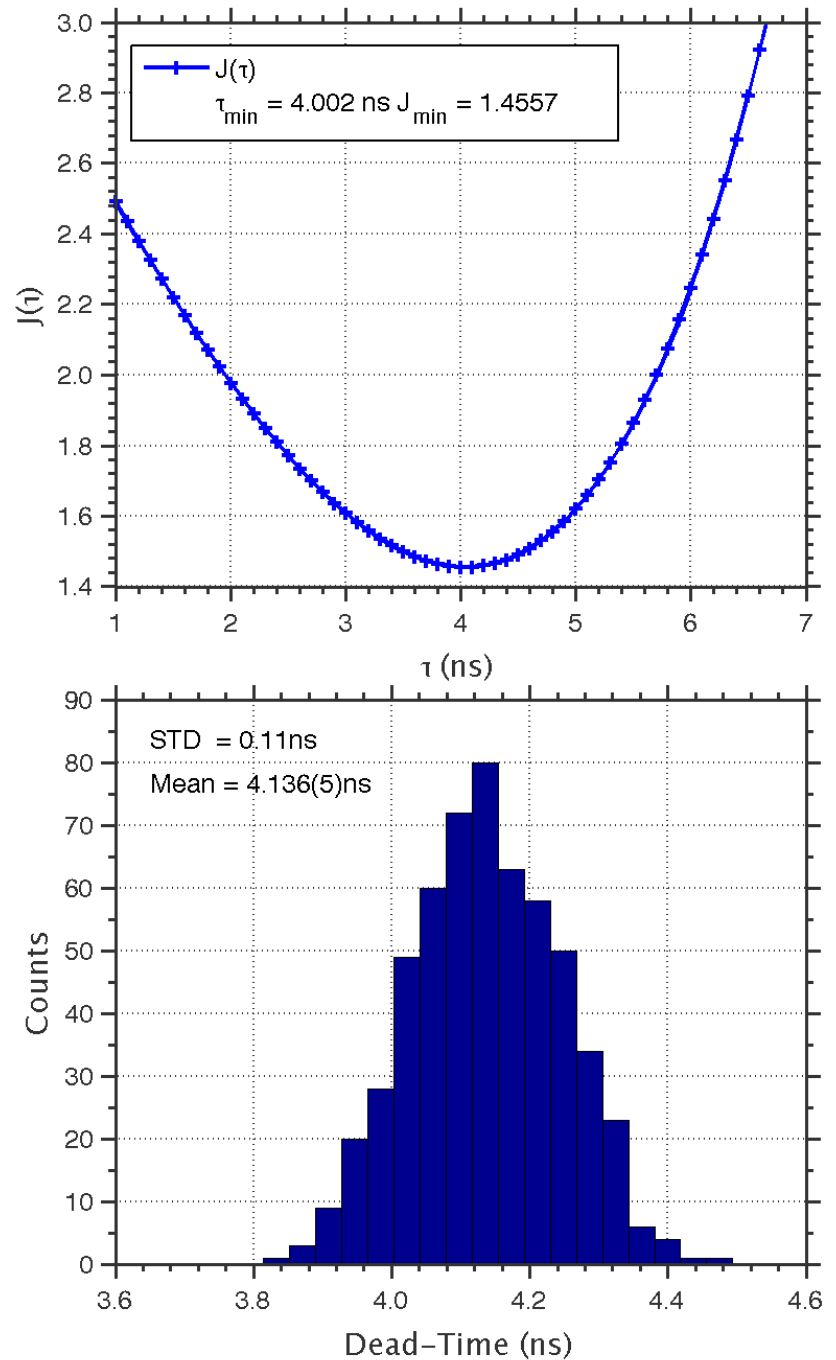

Figure 2. Residual, $J(t, \tau)$, as a function of the dead time, $\tau$, for a sample $1 \mathrm{~min}$ profile for the elastic channel is shown on top. The point of minimum indicated in the legend is found by fitting a parabola. The lower panel shows the histogram of the dead times for the same channel obtained from 580 independent 1 min profiles. The average and standard deviation are indicated.

a $10 \mathrm{~mm}$ shutter is positioned just above the iris and kept in its light-blocking position by a coil mechanism. Interlocks are connected to the power supply and to a light sensor inside a small telescope with a $10^{\circ}$ field of view. The instrument itself is mounted within a special environmental cabinet, including air conditioning and a dehumidifier, due to the harsh environment of Amazonia. 


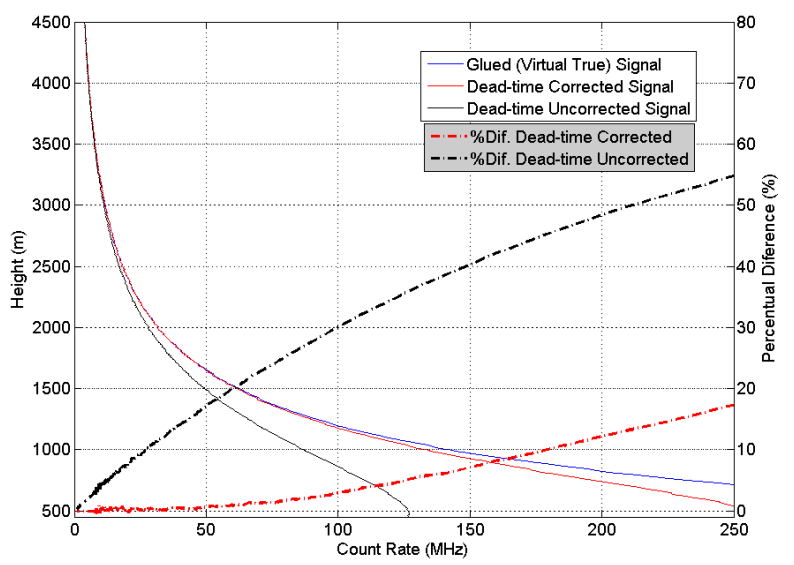

Figure 3. Corrected (thin red) and uncorrected (thin black) count rates $(\mathrm{MHz})$ from a sample $20 \mathrm{~min}$ profile from the elastic channel are shown. The difference (\%) between these and the true count rate (glued, thin blue) is given by the red and black dot-dashed lines, respectively.

\section{Analysis algorithm}

\subsection{Molecular reference}

Rayleigh scattering by atmospheric molecules needs to be accurately estimated before the inversion of lidar signals. The parameters characterizing this type of scattering are well documented in the literature (e.g., McCartney, 1976). The total cross section for Rayleigh scattering in a standard atmosphere $\left(15^{\circ} \mathrm{C}\right.$ and $\left.1013.25 \mathrm{hPa}\right), \sigma_{\mathrm{m}}^{\text {std }}$, is calculated as in Bucholtz (1995), i.e., without the approximation for the refractive index. This is, in turn, computed from the equations provided by Peck and Reeder (1972). The King correction factor for the depolarization of air molecules is computed separately for each constituent using the results from Bates (1984) and combined into a dry air factor following Bodhaine et al. (1999). The standard air $\mathrm{CO}_{2}$ concentration is scaled to a constant value of $375 \mathrm{ppmv}$. The molecular scattering is hence computed as

$\alpha_{\mathrm{m}}(\lambda, z)=N^{\mathrm{std}} \sigma_{\mathrm{m}}^{\mathrm{std}}\left(\lambda, 375 \mathrm{ppmv} \mathrm{CO}_{2}\right) \frac{P(z) / T(z)}{P^{\mathrm{std}} / T^{\mathrm{std}}}$,

where the molecular density in a standard atmosphere, $N^{\text {std }}$, is $2.5469 \times 10^{25} \mathrm{~m}^{-3}$ and $\sigma_{\mathrm{m}}^{\text {std }}$ for 355 and $387 \mathrm{~nm}$ is 2.7589 and $1.9211 \times 10^{-30} \mathrm{~m}^{2}$, respectively.

Radiosondes launched at 00:00 and 12:00 UTC from Ponta Pelada airport at $3.14^{\circ} \mathrm{S} 59.98^{\circ} \mathrm{W}$, approximately $28.5 \mathrm{~km}$ south of the experimental lidar site, were used to provide pressure and temperature profiles. Over a dense tropical rain forest one would expect the thermodynamic profile to be horizontally homogeneous. The proximity of radiosonde site to Manaus city and the Amazon river requires, however, the verification of this hypothesis. Between $30 \mathrm{Au}-$ gust and 5 September 2011, ten collocated soundings were launched during nighttime from the lidar site and compared with the operational ones. Both sites used Vaisala RS92-SGP radiosondes. Figure 4 shows collocated minus operational profiles. The legend indicates the time difference in minutes between the two launches. Pressures and temperatures at the lidar site are lower than those at the airport by about $5 \mathrm{hPa}$ and $1{ }^{\circ} \mathrm{C}$ on average. For our purposes, however, the important result is that the air density, and hence the molecules number concentration, differ by less than $1 \%$.

The molecular backscatter coefficient is calculated from the molecular scattering and phase function considering the depolarization factor, $\rho_{n}$, as

$\beta_{\mathrm{m}}(\lambda, z)=\frac{\alpha_{\mathrm{m}}(\lambda, z)}{4 \pi} P_{\text {ray }}(\pi, \lambda)=\frac{\alpha_{\mathrm{m}}(\lambda, z)}{8 \pi / 3} \frac{2}{2+\rho_{n}}$,

where $\rho_{n}$ for $355 \mathrm{~nm}$ and $387 \mathrm{~nm}$ is 0.0306 and 0.0299 , respectively, which result in molecular lidar ratios of $1.0153 \times 8 \pi / 3 \mathrm{sr}$ and $1.0150 \times 8 \pi / 3 \mathrm{sr}$. The expected elastic return signal from a pure molecular atmosphere can then be calculated as

$P_{\mathrm{m}}\left(\lambda_{0}, z\right)=\frac{1}{z^{2}} \beta_{\mathrm{m}}\left(\lambda_{0}, z\right) \exp \left\{-2 \int_{0}^{z} \alpha_{\mathrm{m}}\left(\lambda_{0}, z^{\prime}\right) \mathrm{d} z^{\prime}\right\}$

which needs to be scaled by a constant $K\left(\lambda_{0}\right)$ determined by comparison with the background (BG) corrected elastic signal, $P\left(\lambda_{0}, z\right)-\mathrm{BG}$. Both $K\left(\lambda_{0}\right)$ and $\mathrm{BG}$ can be found by means of a simple linear regression,

$P\left(\lambda_{0}, z\right)=K\left(\lambda_{0}\right) \cdot P_{\mathrm{m}}\left(\lambda_{0}, z\right)+\mathrm{BG}$.

For the linear relation to hold, no aerosols can be present in the region selected for the regression. Therefore, only data above $8 \mathrm{~km}$ is used, as previous campaigns in the Amazon have shown that the aerosol concentration above this height is negligible (Baars, 2011). This, however, is verified in an interactive approach by calculating the distance between each point and the fitted curve,

$\delta(z)=\frac{P\left(\lambda_{0}, z\right)-\left[K\left(\lambda_{0}\right) \cdot P_{\mathrm{m}}\left(\lambda_{0}, z\right)+\mathrm{BG}\right]}{\sqrt{\chi_{\text {red }}^{2}}}$,

where the reduced chi-square, $\chi_{\text {red }}^{2}$, is used as a measure of the local noise level. Those points where $\delta(z)>3$ or where the signal to noise ratio is $S / N<15$ are removed. Both steps are repeated until no more points are excluded.

\subsection{Aerosol inversions}

During the day, the well-known Klett-Fernald (Klett, 1985; Fernald, 1984) method is used to solve the equation for the elastic lidar return signal,

$$
\begin{aligned}
& P\left(\lambda_{0}, z\right)= \\
& \quad K\left(\lambda_{0}\right) \frac{O(z)}{z^{2}} \beta\left(\lambda_{0}, z\right) \exp \left\{-2 \int_{0}^{z} \alpha\left(\lambda_{0}, z^{\prime}\right) \mathrm{d} z^{\prime}\right\},
\end{aligned}
$$



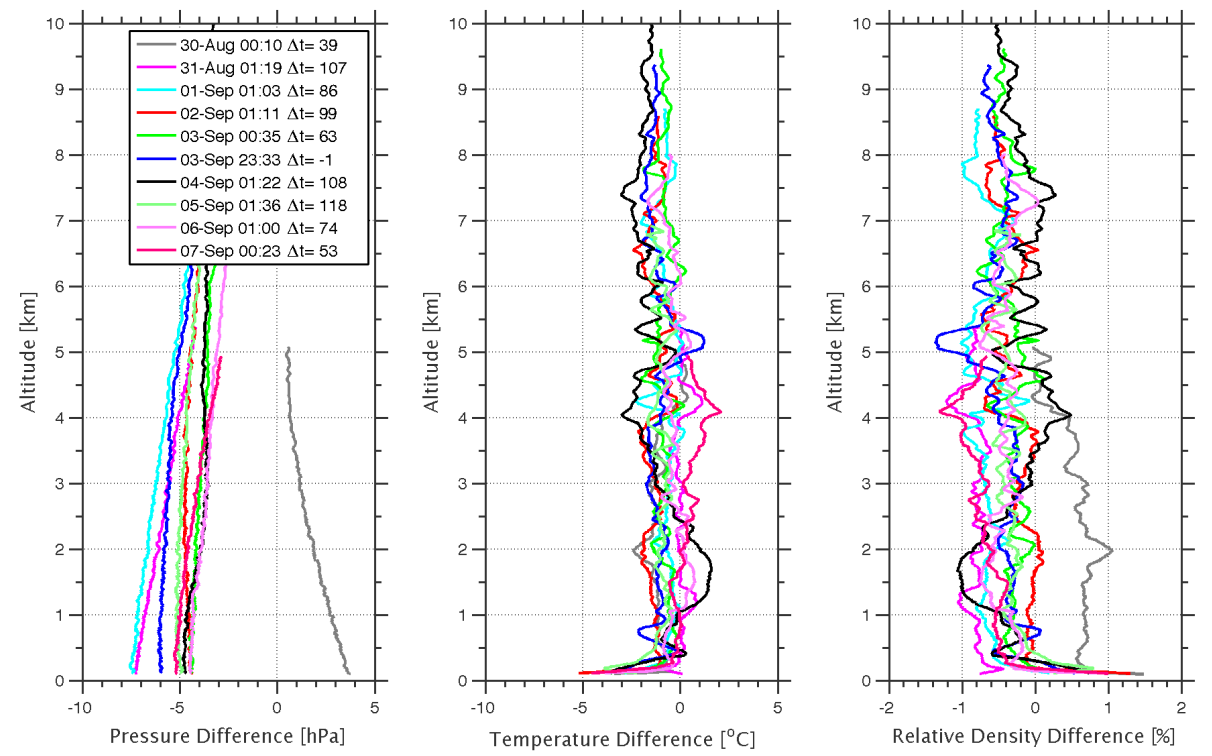

Figure 4. Pressure (hPa, left), temperature $\left({ }^{\circ} \mathrm{C}\right.$, center) and relative air density (\%, right) differences between the Embrapa's and operational's radiosondes are shown. Dates in the legend correspond to the launching time at the lidar site.

where $K\left(\lambda_{0}\right)$ includes all height-independent terms, $O(z)$ is the overlap function, $\beta=\beta_{\mathrm{p}}+\beta_{\mathrm{m}}$ is the total elastic backscatter coefficients and $\alpha=\alpha_{\mathrm{p}}+\alpha_{\mathrm{m}}$ is the total extinction coefficient. Assuming a height independent particle lidar ratio $\left(L_{\mathrm{p}}=\alpha_{\mathrm{p}} / \beta_{\mathrm{p}}\right)$ and having chosen a reference height, $z_{0}$, where the particle contribution is negligible, i.e., $\beta_{\mathrm{m}}\left(z_{0}\right) \gg$ $\beta_{\mathrm{p}}\left(z_{0}\right)$, the solution can be conveniently written as:

$$
\begin{aligned}
& \beta_{\mathrm{p}}(z)=S(z) T\left(z, z_{0}\right) \\
& {\left[\frac{S\left(z_{0}\right)}{\beta_{\mathrm{m}}\left(z_{0}\right)}-2 L_{\mathrm{p}} \int_{z_{0}}^{z} S\left(z^{\prime}\right) T\left(z^{\prime}, z_{0}\right) \mathrm{d} z^{\prime}\right]^{-1}-\beta_{\mathrm{m}}(z),} \\
& T\left(z, z_{0}\right)=\exp \left[-2\left(L_{\mathrm{p}}-L_{\mathrm{m}}\right) \int_{z_{0}}^{z} \beta_{\mathrm{m}}\left(r^{\prime}\right) \mathrm{d} r^{\prime}\right],
\end{aligned}
$$

where $S(z)=P(z) z^{2}$ is the range corrected signal and $L_{\mathrm{m}}$ is the molecular lidar ratio. The accuracy of this solution depends strongly on the molecular character of the reference value $S\left(z_{0}\right)$. This, however, is subject to noise fluctuations as the number of detected photons $P\left(z_{0}\right)$ has a Poisson distribution with $\lambda=\sqrt{P\left(z_{0}\right)}$. In some algorithms discussed in the literature (Fernald, 1984), a small but non-zero value of $\beta_{\mathrm{p}}\left(z_{0}\right)$ is chosen to compensate the fact that $P\left(z_{0}\right) \neq P_{\mathrm{m}}\left(z_{0}\right)$ at the starting point of the integration. There are also algorithms where the reference height is chosen to minimize $\left|P(z)-P_{\mathrm{m}}(z)\right|$. Here the signal is assumed to be intrinsically noisy and an alternative approach is taken. If $P(z)$ has indeed a Poisson distribution around $P_{\mathrm{m}}(z)$, the reference height is considered to be in the middle of the molecular region and $S\left(z_{0}\right)=S_{\mathrm{m}}\left(z_{0}\right)$ is set.
During the night, the inversion method developed by Ansmann et al. (1992) is used to solve the equation for the nitrogen Raman return signal,

$$
\begin{aligned}
P\left(\lambda_{\mathrm{R}}, z\right) & =K\left(\lambda_{\mathrm{R}}\right) \frac{O(z)}{z^{2}} \beta\left(\lambda_{\mathrm{R}}, \lambda_{0}, z\right) \\
& \exp \left\{-\int_{0}^{z}\left[\alpha\left(\lambda_{0}, z^{\prime}\right)+\alpha\left(\lambda_{\mathrm{R}}, z^{\prime}\right)\right] \mathrm{d} z^{\prime}\right\},
\end{aligned}
$$

where the inelastic backscatter coefficient $\beta\left(\lambda_{\mathrm{R}}, \lambda_{0}, z\right)=$ $N(z) \mathrm{d} \sigma\left(\lambda_{\mathrm{R}}, \lambda_{0}, \pi\right) / \mathrm{d} \Omega$ is given in terms of the number density of nitrogen molecules, $N_{\mathrm{R}}$, and the differential cross section for the Raman inelastic scattering, $\mathrm{d} \sigma_{\mathrm{R}} / \mathrm{d} \Omega$. Assuming a wavelength dependence of $\lambda^{-k}$ for both particles and molecules, the solution for the extinction coefficient is given by

$$
\begin{aligned}
& \alpha_{\mathrm{p}}\left(\lambda_{0}, z\right)= \\
& \frac{\frac{\mathrm{d}}{\mathrm{d} z}\left\{\ln \left[\frac{N_{\mathrm{R}}(z) O(z)}{S_{\mathrm{R}}(z)}\right]\right\}-\alpha_{\mathrm{m}}\left(\lambda_{0}, z\right)\left[1+\left(\lambda_{0} / \lambda_{\mathrm{R}}\right)^{k_{\mathrm{m}}}\right]}{1+\left(\lambda_{0} / \lambda_{\mathrm{R}}\right)^{k_{\mathrm{p}}}},
\end{aligned}
$$

where the overlap function was explicitly kept, $S_{\mathrm{R}}$ is the range corrected Raman signal and $k_{\mathrm{p}}$ and $k_{\mathrm{m}}$ are the Angstrom coefficients for particles and molecules, respectively. Having chosen a reference height $z_{0}$ where the particle contribution is negligible, the backscatter coefficient is given by

$$
\begin{aligned}
\beta_{\mathrm{p}}\left(\lambda_{0}, z\right) & =-\beta_{\mathrm{m}}\left(\lambda_{0}, z\right) \\
& +\beta_{\mathrm{m}}\left(\lambda_{0}, z_{0}\right) \frac{S(z) / S_{\mathrm{R}}(z)}{S_{\mathrm{m}}\left(z_{0}\right) / S_{\mathrm{m}, \mathrm{R}}\left(z_{0}\right)} \frac{N_{\mathrm{R}}(z)}{N_{\mathrm{R}}\left(z_{0}\right)}
\end{aligned}
$$



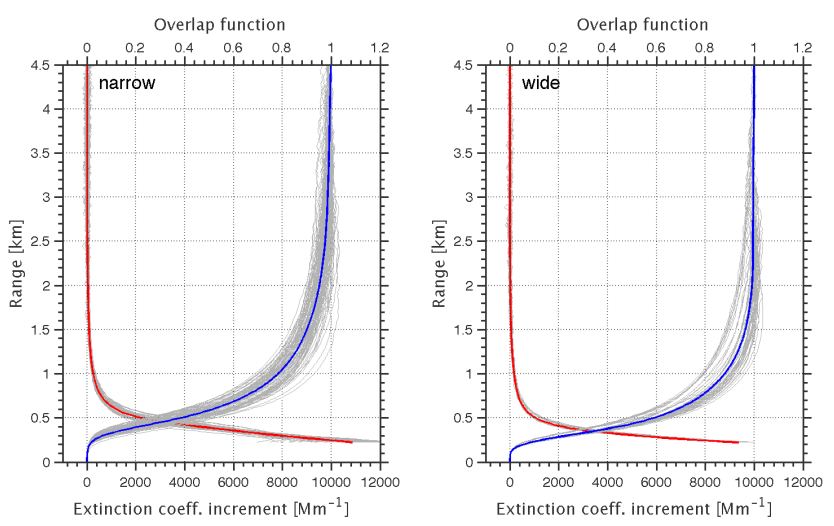

Figure 5. Mean overlap function from 90 (45) cloud and fog free nighttime one-hour profiles measured with a narrow (wide) field stop is shown in blue on the left (right) panel. Mean contribution to the extinction coefficient, as computed from Eq. (14), is shown in red. The gray lines correspond to the individual profiles. The wide field stop is used since 1 August 2012.

$$
\times \exp \left\{\int_{z_{0}}^{z}\left[\alpha\left(\lambda_{0}, z^{\prime}\right)-\alpha\left(\lambda_{\mathrm{R}}, z^{\prime}\right)\right] \mathrm{d} z^{\prime}\right\},
$$

where $S\left(z_{0}\right)$ and $S_{\mathrm{R}}\left(z_{0}\right)$ were replaced by the calibrated molecular values $S_{\mathrm{m}}\left(z_{0}\right)$ and $S_{\mathrm{m}, \mathrm{R}}\left(z_{0}\right)$ after the same arguments used for the Klett inversion. This solution is more stable than the one shown by Ansmann et al. (1992) as it does not depend at all on the noise fluctuations at $z_{0}$.

\subsection{Error Evaluation}

The retrieval of aerosol properties from lidar signals is subject to both statistical and systematic errors (Matthias et al., 2002). Statistical errors either come from the sky background and dark current, i.e related to the to signal detection (Theopold and Bosenberg, 1988), or are introduced when processing the signal, e.g., time averaging during variable atmospheric conditions (Ansmann et al., 1992; Böosenberg, 1998). These errors can be evaluated by analyzing the standard deviation of the measured lidar signal. On the other hand, the systematic errors are difficult to account for as their sources and effects on the signal can be quite different. To name a few, these can come from the estimate: of temperature, pressure and ozone profiles (Ansmann et al., 1992); of the Angstrom coefficient (Ansmann et al., 1992; Whiteman, 1999); of the multiple scattering effects (Ansmann et al., 1992; Wandinger, 1998; Whiteman, 1999); of the unknown factor of incomplete overlap between the transmitted laser beam and the telescope field of view (Wandinger and Ansman, 2002); of the reference altitude; and of the particle lidar ratio for the elastic inversion.

For a bi-axial lidar system with a narrow field of view, such as the system described in this paper, the largest source of systematic error in the short range is the overlap function. To

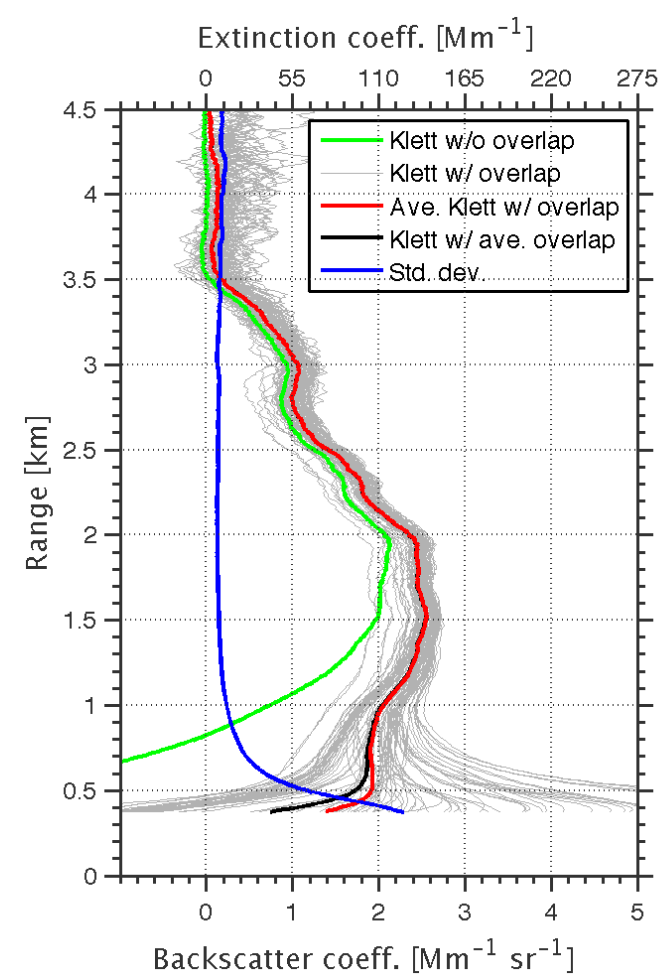

Figure 6. Backscatter coefficient obtained with the Klett algorithm without overlap correction (green) and with the average overlap (black) are shown. The backscatter coefficient obtained for each of the 90 overlaps measured with a narrow field stop (gray), their average (red) and standard deviation (blue) are also shown. Data from 1 September 06:30 p.m. to 2 September 05:00 a.m. was used. The extinction scale on top was scaled with $L_{\mathrm{p}}=55 \mathrm{sr}$.

obtain this overlap function, we used the iterative approach proposed by Wandinger and Ansman (2002) with a constant particle lidar ratio of $55 \mathrm{sr}$ for the Klett algorithm (to be discussed in Sect. 4).

All the data from July 2011 to November 2012 were divided into one-hour intervals and pre-processed to select the nighttime hours with no clouds or fog. About 90 one-hour averaged profiles were selected for the period before $1 \mathrm{Au}$ gust 2012, and 40 for the period after that. The distinction being the change of the field stop size from $4 \mathrm{~mm}$ (narrow) to $7 \mathrm{~mm}$ (wide), respectively, which increased the field of view of the telescope and hence lowered the maximum overlap. Figure 5 shows in gray the results obtained from the application of the algorithm to each selected one-hour intervals and in blue the mean value. With the wide (narrow) field stop the overlap is complete at about $1.8 \mathrm{~km}(3 \mathrm{~km})$. Expanding the first term in Eq. (12), one find the contribution from the overlap function to the extinction coefficient as obtained by the Raman inversion (Matthias et al., 2002; Baars, 2011): 


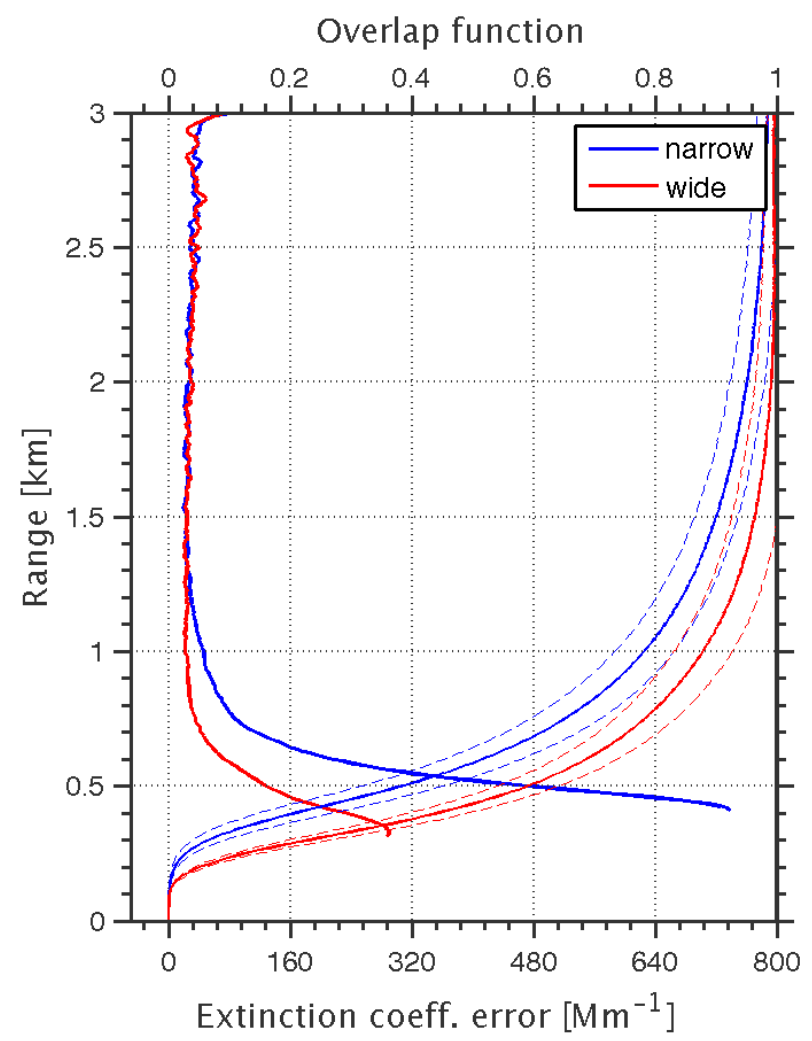

Figure 7. Estimation of the error in the extinction coefficient from the uncertainty in the overlap function are shown in thick lines. For reference, the mean overlap functions and the $95 \%$ confidence level are to the right. Red (blue) colors are used for the wide (narrow) the field stops.

$\Delta \alpha_{\mathrm{p}}\left(\lambda_{0}, z\right)=\frac{\frac{\mathrm{d}}{\mathrm{d} z}[\ln O(z)]}{1+\left(\lambda_{0} / \lambda_{\mathrm{R}}\right)^{k_{\mathrm{p}}}}$.

The contribution to the extinction from each individual one-hour period is shown also in Fig. 5 in gray and the mean value in red. For the cases with a wide (narrow) field stop, the overlap correction is very important for altitudes below $1 \mathrm{~km}(1.5 \mathrm{~km})$. It should be noted that, because Eq. (14) involves the derivative of $O(z)$ it stops giving an important contribution much before the altitude where $O(z)=1$. To calculate the influence of the overlap function on the Elastic retrieval (Eq. 9), a Monte Carlo approach is more appropriate (Matthias et al., 2002). The average nighttime profile for 1 September was inverted without overlap correction and with each overlap correction estimated with the Raman approach for the narrow field of view (see Fig. 6). For the Klett inversion, it is important to account for the overlap below $2.5 \mathrm{~km}$. Another important point to consider regarding the overlap correction is the uncertainty in the values estimated with an average overlap. This uncertainty can be estimated from the standard deviation of the gray lines shown in Figs. 5

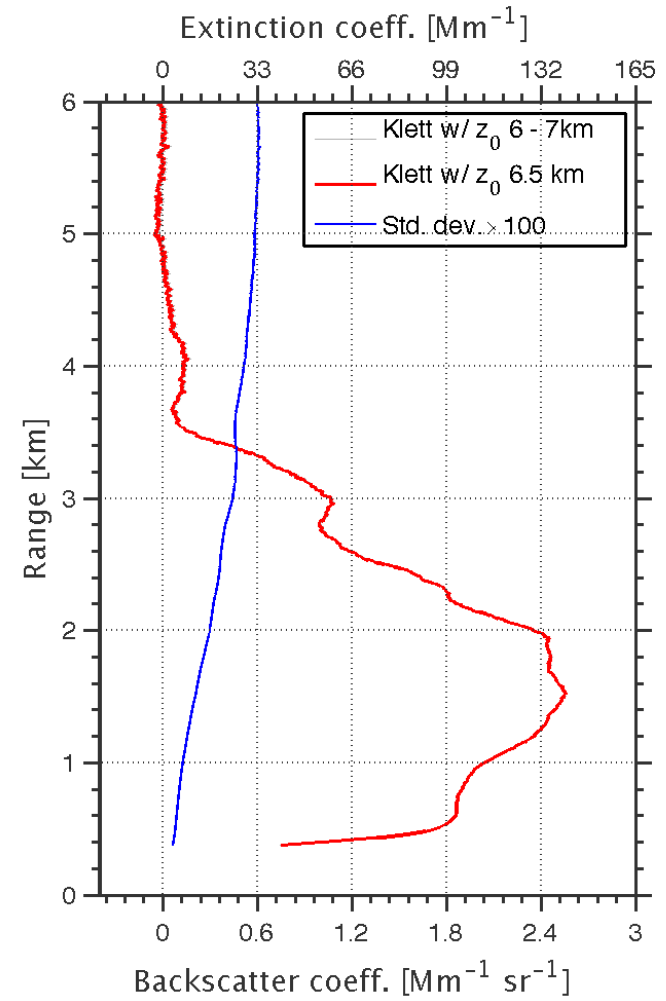

Figure 8. Backscatter coefficient obtained with the Klett algorithm with reference height $z_{0}$ varying from 6 to $7 \mathrm{~km}$ in steps of $50 \mathrm{~m}$ (gray) and the default inversion with $z_{0}=6.5 \mathrm{~km}$ (red) are shown. The standard deviation (blue) is multiplied by 100. Data from 1 September 06:30 p.m. to 2 September 05:00 a.m. was used. The extinction scale on top was scaled with $L_{\mathrm{p}}=55 \mathrm{sr}$.

and 6. This analysis is shown in Figs. 6 (for Klett) and 7 (for Raman). For the Klett backscatter, this uncertainty is less than $0.25 \mathrm{Mm}^{-1} \mathrm{sr}^{-1}$ above $1 \mathrm{~km}$ and $1 \mathrm{Mm}^{-1} \mathrm{sr}^{-1}$ at $500 \mathrm{~m}$. For the Raman extinction, at $500 \mathrm{~m}$, the uncertainty for a wide (narrow) field stop is about $140 \mathrm{Mm}^{-1}\left(480 \mathrm{Mm}^{-1}\right)$.

The Monte Carlo approach was also used to access the uncertainty from the choice of the reference height, $z_{0}$. The same average nighttime profile for 1 September was used and both the Klett and Raman inversions were performed with $z_{0}$ varying from 6 to $7 \mathrm{~km}$ in steps of $50 \mathrm{~m}$. Figure 8 shows the result for the Klett backscattering coefficient, where the inversion with the different $z_{0}$ (gray) are all under the curve for $z_{0}=6.5 \mathrm{~km}$ (red) as they are very similar. The standard deviation shown in blue was multiplied by 100 and is largest closer to the reference height where it reaches $0.6 \times 10^{-2} \mathrm{Mm}^{-1} \mathrm{sr}^{-1}$. This is very small compared to the typical particle backscatter because the algorithms normalizes the lidar signal to the molecular value at the reference altitude. A similar negligible uncertainty was found for the Raman inversion (not shown).

The elastic inversion depends strongly on the choice of the particle lidar ratio, and it is therefore important to quantify 


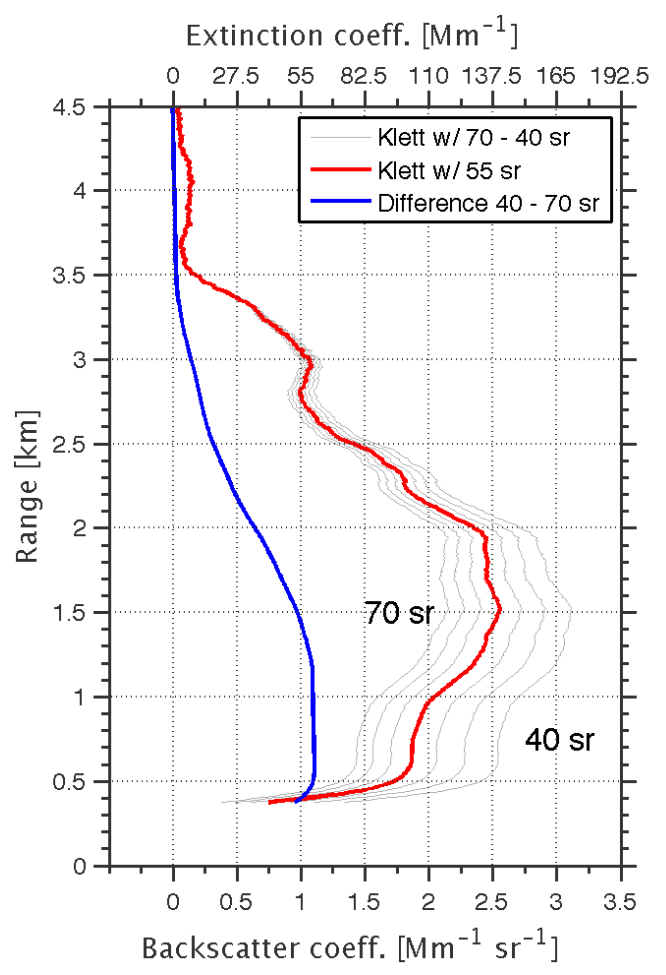

Figure 9. Backscatter coefficient obtained with the Klett algorithm using particle lidar ratios from 40 to $70 \mathrm{sr}$ in steps of $5 \mathrm{sr}$ (gray) and the default inversion with $55 \mathrm{sr}$ (red) are shown. The difference of the backscatter obtained with 40 and $70 \mathrm{sr}$ (blue) is shown as an indication of the uncertainty. Data from 1 September 06:30 p.m. to 2 September 05:00 a.m. was used. The extinction scale on top was scaled with $L_{\mathrm{p}}=55 \mathrm{sr}$.

the associated uncertainty. As the analysis routine uses $55 \mathrm{sr}$, the Klett inversion was repeated for values ranging from 40 to $70 \mathrm{sr}$ in steps of $5 \mathrm{sr}$ and the result is shown in Fig. 9. This \pm 15 sr variation in the particle lidar ratio was considered after Baars et al. (2011). Higher particle lidar ratio correspond to lower backscatter coefficient, as expected, and the difference between the two extremes is shown in blue as a measure of the associated uncertainty. It is about $1 \mathrm{Mm}^{-1} \mathrm{sr}^{-1}$ below $1 \mathrm{~km}$ and negligible above $3.5 \mathrm{~km}$.

The uncertainty in the Raman extinction coefficient associated with the uncertainty in the angstrom coefficient was also evaluated using the Monte Carlo approach. The AERONET value of $1.2 \pm 0.4$ (Schafer et al., 2008) was varied, and the changes where negligible compared to the uncertainties discussed above.

\subsection{Cloud base and top heights}

The base and top heights of clouds are found using an algorithm similar to the one applied by Barja (2002). The algorithm uses only the signal and not its derivatives, as is usual in other methods appearing in the literature (e.g., Wang and Sassen, 2001). It is based on the fact that the intensity of the lidar return signal in a pure molecular atmosphere decreases monotonically with increasing range and that an abrupt signal increment is found only when going trough a cloud layer. Therefore, the algorithm searches for a maximum in the signal and the corresponding previous minimum to determine the height of maximum backscattering and cloud base, respectively. The cloud top is defined to be at the height at which the signal returns to behave as pure molecular. For thick clouds, where the signal is completed attenuated, an apparent cloud top is defined at the height at which the signal returns to the level it had at cloud base. This value, however, is not used for the analysis of the cloud top altitudes. Although the algorithm can be described in such simple terms, its implementation demands filters and statistical tests to remove the influence of noise, which are both system dependent. The algorithm steps are

1. compare the raw signal in each bin with its first neighbors and calculate all local maxima and corresponding previous minima;

2. apply a 3-point moving average to the raw signal and calculate all local maxima and corresponding minima of the filtered signal;

3. exclude those $\max / \mathrm{min}$ pairs that are not found at the same time in the raw and filtered signals;

4. select $\mathrm{max} / \mathrm{min}$ pairs corresponding to clouds by comparing the difference between raw signal at maximum and minimum with the difference between raw and filtered signals at maximum;

5. select the cloud base height as the first minimum found when searching upwards and select the apparent cloud top height where the raw signal is equal or less than the signal at cloud base;

6. find the height of maximum signal between base and top, i.e., the maximum backscattering height, and take note of the intermediary minima as they indicate sublayers of the same cloud;

7. repeat steps 5-7 for the region above cloud top to identify other cloud layers.

The pairs of base and top from the above steps are an approximation of the true base and top heights. They are used as a reference for the inversion algorithm to exclude the cloudy part of the profile thus allowing for the calculation of the molecular and particle backscattering coefficients. The final base and top heights are defined as the heights where the particle backscattering coefficient is larger by two standard deviations than the average backscattering coefficient between 19 and $20 \mathrm{~km}$ as in Goldfarb et al. (2001). 

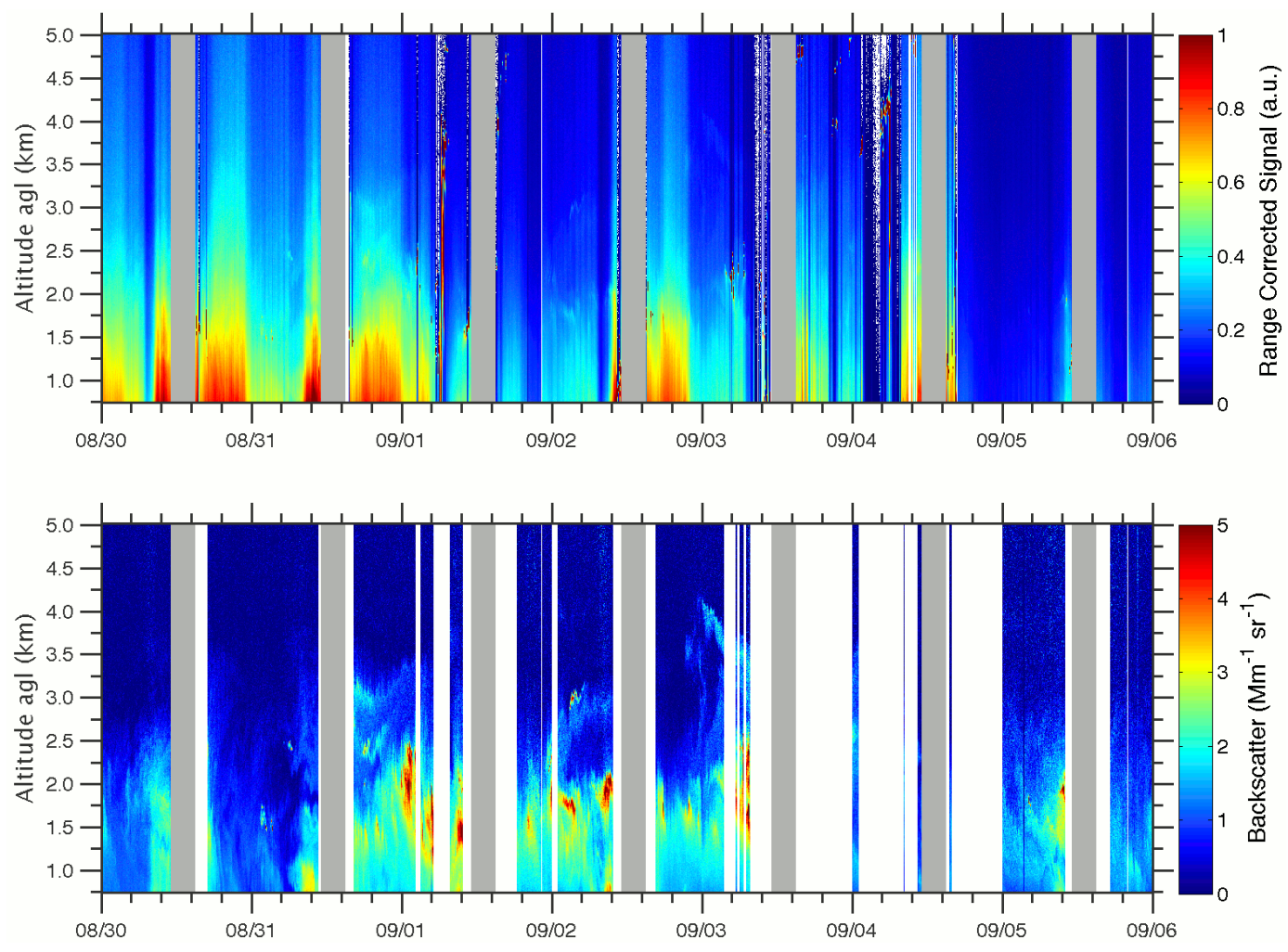

Figure 10. Range and background corrected signal (top, a.u.) and aerosol backscatter coefficient (bottom, $\mathrm{Mm}^{-1} \mathrm{sr}^{-1}$ ) obtained from the elastic channels are shown below $5 \mathrm{~km}$ from 30 August to 6 September 2011. Inversion assumed a particle lidar ratio of $55 \mathrm{sr}^{-1}$. Gray and white regions correspond to local solar noon and clouds, respectively.

\section{Results and discussion}

Results presented correspond to measurements taken from 30 August to 6 September 2011. Through this week an intensive campaign for calibration of the water vapor channel of the UV Raman lidar was conducted. Besides having the thermodynamic profile from the collocated soundings, this period is also optimal because maintenance and verification were performed on a daily basis by an on site team and because of the low cloud cover typical of the Amazon dry season.

\subsection{Vertical profiles of aerosols}

The aerosol backscatter coefficient was obtained from the elastic channels using Eqs. (9) and (10) with a particle lidar ratio of $55 \mathrm{sr}$, which is typical for aged biomass burning aerosols found in this region during the transition from the dry to wet seasons (Baars et al., 2012). This is shown in Fig. 10 where the grayed regions correspond to local solar noon when the instrument was not operated. Other data not shown corresponds to cloud, precipitation or fog events that can be identified in the range corrected signal (upper panel). The same panel also shows steps in the power of the received signal. These stem from changes in the laser power due to temperature fluctuations inside the cabinet, as the air conditioning tries to keep a constant temperature of $28^{\circ} \mathrm{C}$. The aerosol backscatter coefficient does not show these features as it is calibrated independently of the laser power. Aerosol layers with values from 3 to $5 \mathrm{Mm}^{-1} \mathrm{sr}^{-1}$ are found from 1 to 3 September above $1.5 \mathrm{~km}$, possibly indicating longrange transport. There were events where the aerosol was washed out after precipitation and backscatter was reduced significantly (e.g., 30 August 02:00 p.m.) but events where the aerosol loading remained the same were much more often (e.g., 31 August 02:00 p.m., 1 September 06:00 a.m., 2 September 03:00 p.m. and 3 September 07:00 a.m.).

Figure 11 shows the backscatter and extinction coefficients calculated independently with the Raman algorithm during nighttime (18:30 to 05:50 LT). An Angstrom coefficient of 1.2 was used as an average value for August-October in this region, obtained from AERONET measurements (Schafer et al., 2008). $5 \mathrm{~min}$ profiles and a lower vertical resolution of $75 \mathrm{~m}$ were used. Aerosol plumes with backscatter coefficient larger than $3 \mathrm{Mm}^{-1} \mathrm{sr}^{-1}$ were also seen on 1 and 2 September and an aerosol layer between 1 and $2.5 \mathrm{~km}$ can be identified. This elevated layer appears at heights typical of biomass burning plumes transported over long distances, as characterized by previous lidar studies in the region (Baars et al., 2012). Largest values were around $150 \mathrm{Mm}^{-1}$ inside 

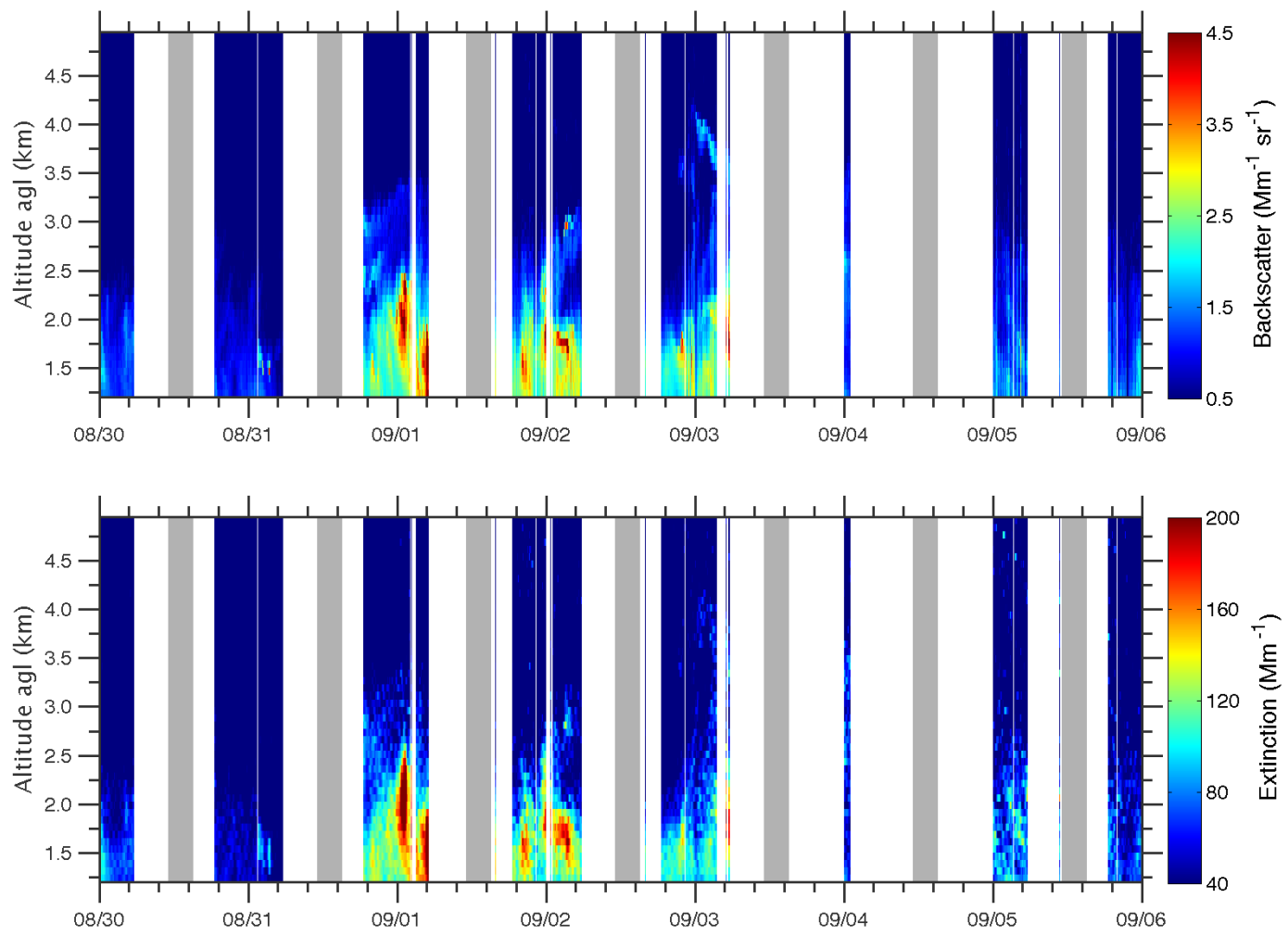

Figure 11. Aerosol backscatter (top, $\mathrm{Mm}^{-1} \mathrm{sr}^{-1}$ ) and extinction (bottom, $\mathrm{Mm}^{-1}$ ) obtained from a Raman inversion are shown above $1 \mathrm{~km}$ from 30 August to 6 September 2011. Gray and white regions correspond to local solar noon and clouds, respectively.

the plume. Extinction coefficients close to ground level (at about $1 \mathrm{~km}$ ) ranged from 40 to $100 \mathrm{Mm}^{-1}$ at $355 \mathrm{~nm}$, which is compatible with the values measured at ground level by Artaxo et al. (2013) during the dry season $\left(10-40 \mathrm{Mm}^{-1}\right.$ at $670 \mathrm{~nm}$ ). Extinction coefficients from the Raman algorithm are much more noisy than the elastic inversion, owing to the derivative in Eq. (12). To analyze the particle lidar ratio, the average profiles were calculated for the days with largest aerosol loading and are shown in Fig. 12. The lidar ratio was computed from the Raman extinction and backscatter coefficients larger than $10 \mathrm{Mm}^{-1}$ and $0.2 \mathrm{Mm}^{-1} \mathrm{sr}^{-1}$, respectively. Values found are about 45 to $65 \mathrm{sr}$ compatible with what is expected for biomass burning aerosols and explaining why the elastic inversion with fixed particle lidar ratio of $55 \mathrm{sr}$ showed good results.

\subsection{Aerosol optical depth}

The aerosol optical depth can be obtained from the light extinction by vertically integrating each profile. However, as the partial overlap significantly impacts the extinction below $1.2 \mathrm{~km}$ (Fig. 5), integrating over this region could lead to unrealistic results. Therefore, we assumed a well-mixed boundary layer with a constant extinction up to $1.2 \mathrm{~km}$, which will be justified below, and calculated the column AOD from all the 1 min profiles of the Klett and Raman extinction coefficients. Figure 13 shows a scatter plot of the elastic AOD vs. the Raman AOD for 4435 nighttime profiles. There is a very good agreement and the linear and angular coefficients are statistically significant at $95 \%$ confidence level to be compatible with 0 and 1 , respectively. As the elastic AOD is similar to the Raman AOD, we used the profiles measured during daytime to validate our lidar measurements against the collocated AERONET station. The AERONET AOD at $355 \mathrm{~nm}$ was estimated from that at $340 \mathrm{~nm}$ using the Angstrom coefficient between $340-380 \mathrm{~nm}$. A good agreement was found, as shown in Fig. 14, and AERONET measurement around local noon nicely matches the lidar data before and after this period. Remotely sensed aerosol optical depth measurements at $550 \mathrm{~nm}$ were taken from the MODIS (The MODerate resolution Imaging Spectroradiometer Remer et al., 2005) Atmosphere Products, MOD04L2 and MYD04L2, Collection 5. MODIS AOD was averaged in an area of $40 \mathrm{~km} \times 40 \mathrm{~km}$ around the site and scaled to $355 \mathrm{~nm}$ using an averaged Angstrom coefficient of 1.11 between $380-500 \mathrm{~nm}$ estimated by AERONET. MODIS-Aqua agrees with both AERONET and lidar measurements, while MODIS-Terra do not. Very few points are available, however, and no definitive conclusion can be drawn from this comparison.

For a quantitative validation, the lidar data were averaged in time around each AERONET measurement and compared 

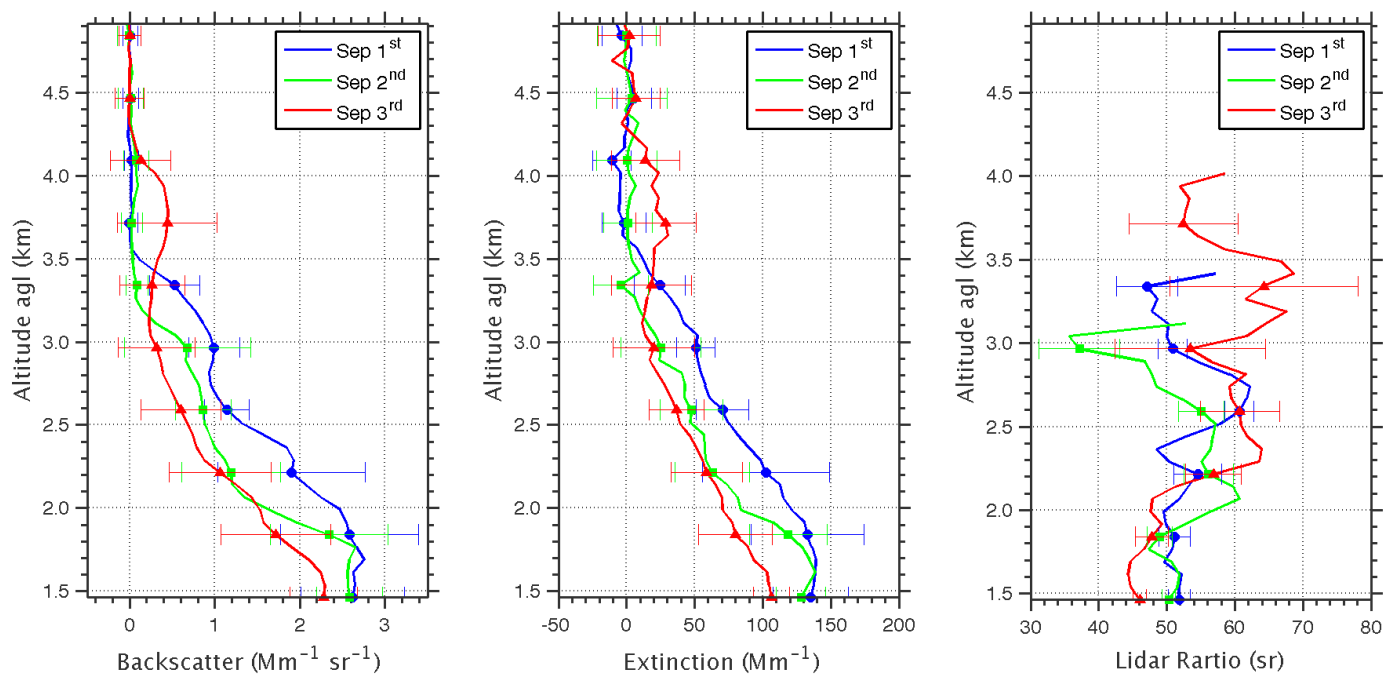

Figure 12. Average aerosol backscatter (left, $\mathrm{Mm}^{-1} \mathrm{sr}^{-1}$ ), extinction (middle, $\mathrm{Mm}^{-1}$ ) and particle lidar ratio (right, sr) obtained from a Raman inversion are shown for days 1, 2 and 3 September 2011.

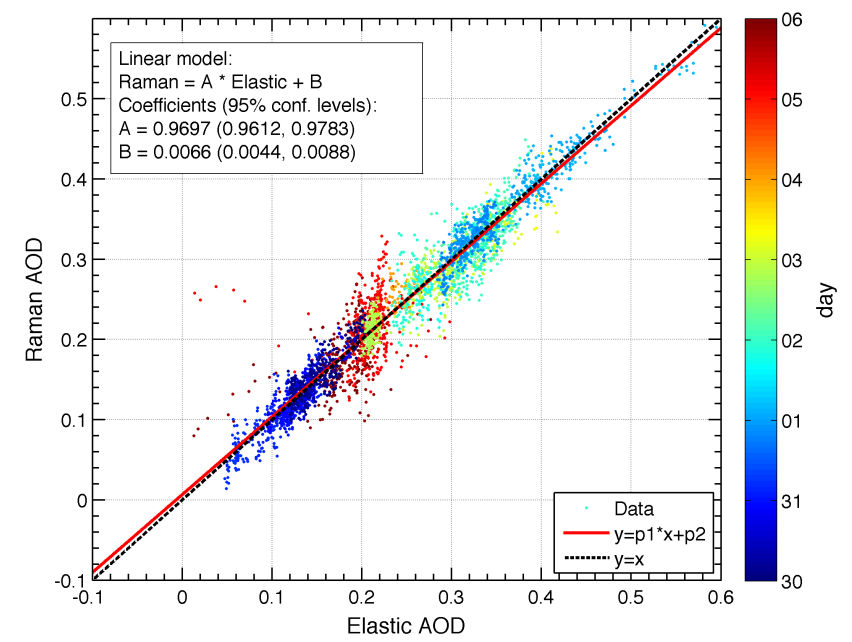

Figure 13. Aerosol optical depth at $355 \mathrm{~nm}$ obtained from the Raman inversion is shown as a function of the optical depth from the elastic inversion for 4435 nighttime cloud-free 1 min profiles between 30 August and 6 September 2011. Colors indicate day of month. The two lines are the linear regression (continuous red) and the reference $y=x$ (dashed).

one by one. As the averaging time window and the height of the constant extinction near ground are somewhat arbitrary, the ranges of possible values were explored for determining the best choice. The time window width was varied from 1 to $60 \mathrm{~min}$, while the altitude of the layer with constant extinction was varied from 0.5 to $2 \mathrm{~km}$. Upper panel of Fig. 15 shows the correlation between the time series of AERONET and lidar AODs as a function of these two parameters. Highest values are found around 1.25 and $1.6 \mathrm{~km}$. A high correlation value, however, does not mean that AERONET and lidar values are close, hence the root mean square error was calculated and is shown in the lower panel. The minimum error is found when assuming a constant extinction below $1.3 \mathrm{~km}$ and doing a $30 \mathrm{~min}$ time average, in good agreement with our previous choice of $1.2 \mathrm{~km}$ based on the overlap uncertainty. Having defined the best parameters, a comparison of the AERONET AOD and the elastic lidar AOD was performed and is shown in Fig. 16. The angular coefficient is compatible with 1 and RMSE is only 0.06 , comparable to the AERONET AOD uncertainty.

\subsection{Back trajectories}

For identifying the source of aerosol particles observed during this week, backward trajectories from the Hysplit model (Draxler and Hess, 1998) and fire spots identified by the $I n$ stituto Nacional de Pesquisas Espaciais (INPE) using a combination of satellites ${ }^{1}$ were used. As the largest AOD values $(\sim 0.7)$ were measured on 3 September (Fig. 16), back trajectories were started at 12:00 UTC of that day from the height of maximum extinction $(\sim 1.5 \mathrm{~km}$, see Fig. 11$)$. Hysplit was run in ensemble mode, by shifting the starting point by one model grid box up/down, east/west and north/south. These 27 different trajectories are shown in Fig. 17 with all fire spots observed between 30 August to 1 September. Some trajectories could carry biomass burning aerosol as they cross nearby fire spots in West Para and more distant ones in East Para and Maranhão. Other trajectories, however, come straight from the ocean and should bring clean air. Local sources of fires could also contribute. The dilution of the polluted air masses could explain the large variations observed in AOD during this week, from below 0.05 up to 0.75 , with a rather constant particle lidar ratio (Fig. 11).

\footnotetext{
${ }^{1} \mathrm{http} / /$ www.inpe.br/queimadas/
} 


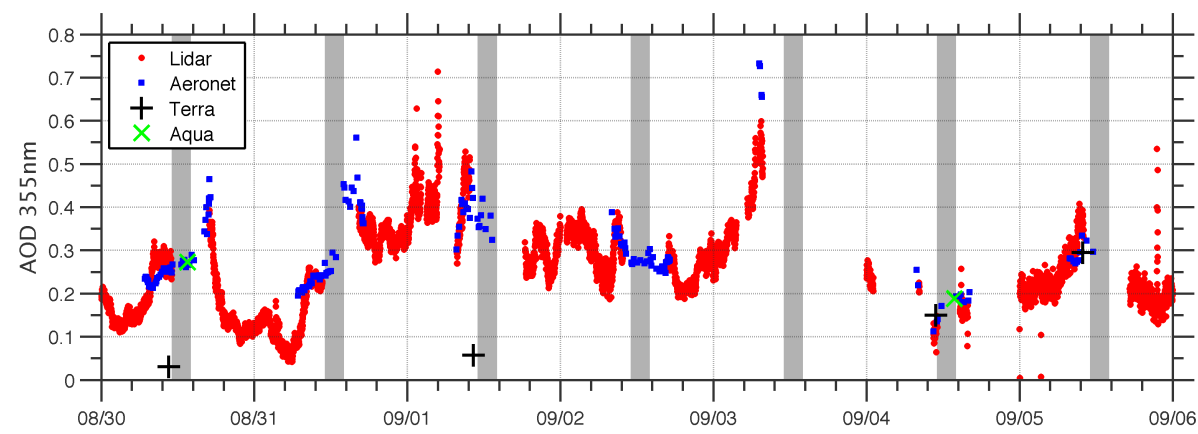

Figure 14. The time series of aerosol optical depth at $355 \mathrm{~nm}$ obtained from the elastic inversion (red), AERONET (blue), MODIS-Terra (black) and MODIS-Aqua (green) are shown between 30 August and 6 September 2011. Gray regions correspond to local solar noon.
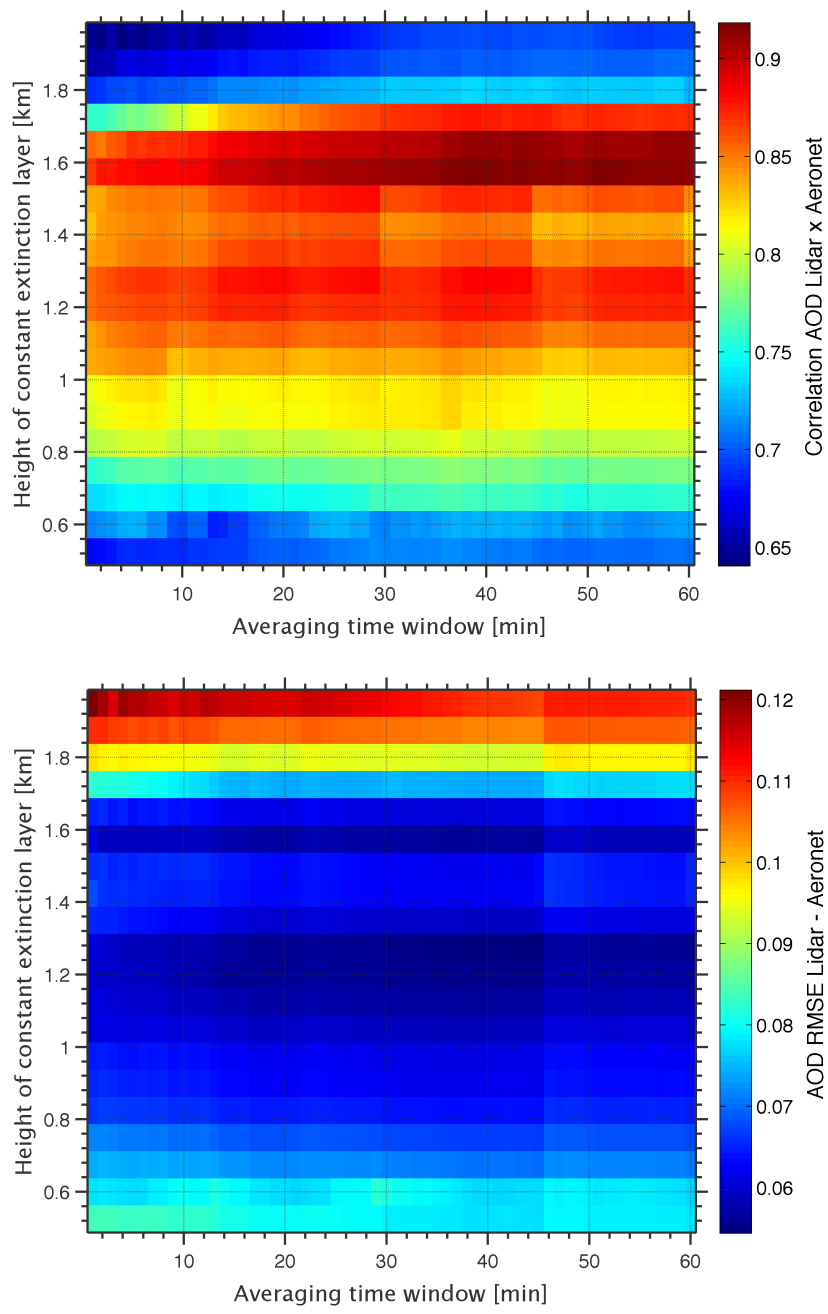

Figure 15. Time correlation (top) and root mean square error (RMSE, bottom) between AERONET AOD and elastic lidar AOD time series are shown as a function of the averaging time window and the height of the constant extinction layer.

\subsection{High clouds geometrical characteristics}

Figure 18 shows the logarithm of range and background corrected signal at $355 \mathrm{~nm}$ for altitudes above $5 \mathrm{~km}$ during the intensive campaign. As in the previous results, lacking measurements around local solar noon is due to the high sun elevation. Other missing data at these altitudes are produced by the low clouds that attenuate the beam at lower levels. The presence of high clouds is easily depicted by the highest values in the signal, shown in red. These high clouds are very frequent and appear at altitudes from 8 to $16.5 \mathrm{~km}$, with higher activity after the first two days.

The high cloud base and top heights found by our automatic algorithm are shown in the same figure, where the green lines indicate the $-25^{\circ} \mathrm{C}$ and the thermal tropopause heights obtained from the radiosondes. There is a good agreement between the identified cloud base (black + ) and top (magenta circle) and the cloud position determined by visual inspection of the signal. However, there are also some base and top heights detected that have no correspondence in the raw signal, for instance, on 5 September 2011 between 09:00 and 10:00 LT. The explanation is that while the background corrected signal is shown only for values above three standard deviations above the background, the high cloud algorithm processes the raw signal. The base and top altitudes found during this period are similar to those found before and after, hence indicating a single high cloud layer. This means that the algorithm has discrimination power even at $S / N$ below 3.

In Fig. 18 there are persistent high clouds from the third to the last day of measurement. The bases and tops are in the range expected for tropical latitudes cirrus (e.g., Immler and Schrems, 2002), with top heights around $15 \mathrm{~km}$ or higher and base heights around $9 \mathrm{~km}$ or higher. These tropical tropopause cirrus clouds may have originated from deep convection in the region, as 5 deep convection events with rain rates between 25 and $222 \mathrm{~mm} \mathrm{~h}^{-1}$ were measured by the collocated weather station. The accumulated precipitation on 1, 3 and 5 September, was 9.35, 28.68 and $17.51 \mathrm{~mm}$. The total precipitation during the intensive campaign was $57.79 \mathrm{~mm}$, 
Table 1. Average geometrical characteristics (base, top and maximum backscattering height) and frequency of occurrence of cirrus clouds in the measurement site near Manaus city during 30 August and 7 September 2011.

\begin{tabular}{lrrrrrrrrrr}
\hline & All & $8 / 30$ & $8 / 31$ & $9 / 1$ & $9 / 2$ & $9 / 3$ & $9 / 4$ & $9 / 5$ & $9 / 6$ & $9 / 7$ \\
\hline Profiles with cirrus clouds & 983 & 8 & 36 & 160 & 146 & 198 & 92 & 157 & 116 & 70 \\
Occurrence Frequency (\%) & 60 & 3 & 15 & 70 & 61 & 83 & 59 & 67 & 53 & 60 \\
Quantity of cirrus layer & & 2 & 1 & 3 & 3 & 3 & 3 & 3 & 3 & 3 \\
Base (km) & 11.5 & 12.0 & 13.9 & 12.6 & 12.5 & 10.9 & 11.4 & 10.7 & 11.3 & 10.2 \\
Top (km) & 13.4 & 12.6 & 14.5 & 14.2 & 14.0 & 13.0 & 13.9 & 12.7 & 13.5 & 12.4 \\
Max. back. (km) & 12.8 & 12.4 & 14.2 & 13.6 & 13.5 & 12.2 & 13.0 & 12.1 & 12.7 & 12.0 \\
\hline
\end{tabular}

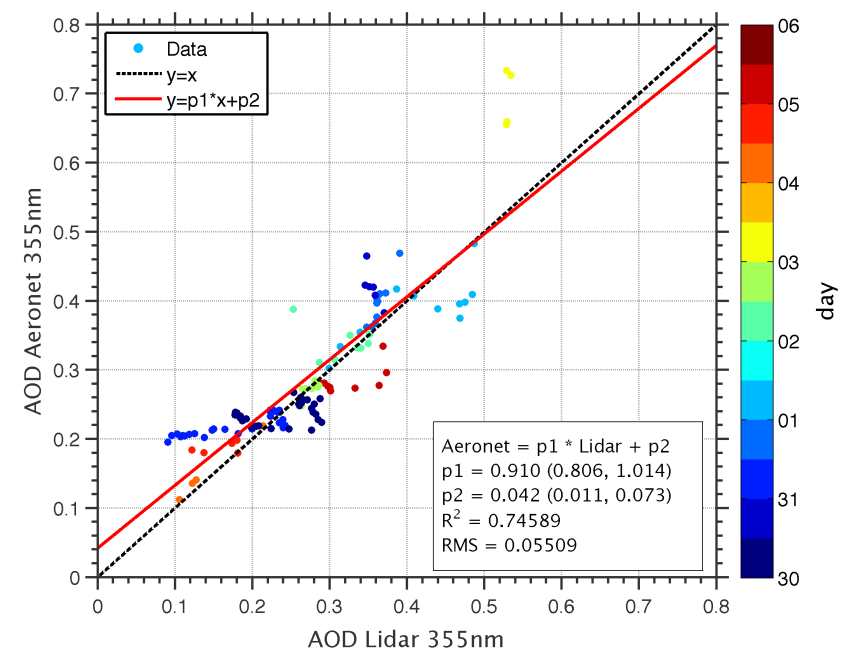

Figure 16. Aerosol optical depth at $355 \mathrm{~nm}$ from AERONET as a function of that obtained from the elastic inversion is shown for the coincident measurements between 30 and 6 September 2011. Lidar extinction profiles were averaged in a $30 \mathrm{~min}$ window and integrated from the reference altitude down to the ground, assuming a constant extinction below $1.3 \mathrm{~km}$.

half of that accumulated in September $(113.5 \mathrm{~mm})$. It is also interesting to note the presence of very optically thick clouds as high as $8-12 \mathrm{~km}$. These seem to be the stratiform part of convective towers as they are found at increasingly higher altitudes (e.g., 1, 3, 5 and 6 September). At 15:00 LT these clouds are around 6-8 km and at 18:00-21:00 LT they are at the tropopause, thus in agreement with the diurnal cycle of local convection in the Amazon (e.g., Machado et al., 2002). This is a strong indication that these cirrus clouds are produced by deep convection, but further analysis with satellite images and back trajectories will be performed in a upcoming study.

Table 1 summarizes the cloud measurements. During the whole period the mean value of base, top and maximum backscattering heights were $11.5,13.4$ and $12.8 \mathrm{~km}$, respectively. The maximum/minimum values for these characteristics during overall period were $17.9 / 6.0 \mathrm{~km}, 19.5 / 6.5 \mathrm{~km}$ and $19.2 / 6.4 \mathrm{~km}$, respectively. On average, the maximum backscattering heights are closer to the top altitude. From the

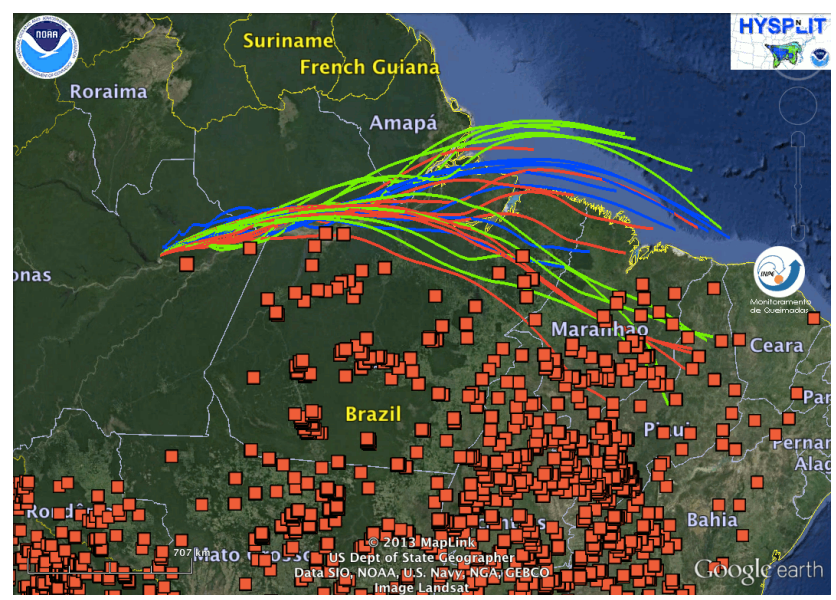

Figure 17. Back trajectories from the Hysplit model from NOAA and fire spots from Instituto Nacional de Pesquisa Espaciais (INPE)'s fire detection algorithm are shown over a Landsat image of the region obtained with Google Earth. Hysplit was run in ensemble mode, with trajectories starting from $1.5 \mathrm{~km}$ on 12:00 UTC 3 September. All fire spots from 30 August to 1 September are shown.

algorithm, it was also obtained the multiple layers of clouds and the sub layers structure inside these high clouds. Up to 3 high clouds layers were detected during almost overall period. Only the first two days have 1 or 2 layers and also correspond to the lowest high cloud frequency occurrence, with only 3 and $15 \%$, respectively.

\section{Conclusions}

This paper described a permanent UV Raman lidar station, which become fully operational in the central Amazon in July 2011. The system was designed for unattended, continuous measurements of aerosols and water vapor aiming to study and monitor the atmosphere on the weather to climatic time scales. The automated data acquisition and the possibility to monitor the instrument over the internet reduced the operational field costs of maintaining on-site personnel and enabled extended hours of daily data collection when compared to a manually operated systems. This new scientific 

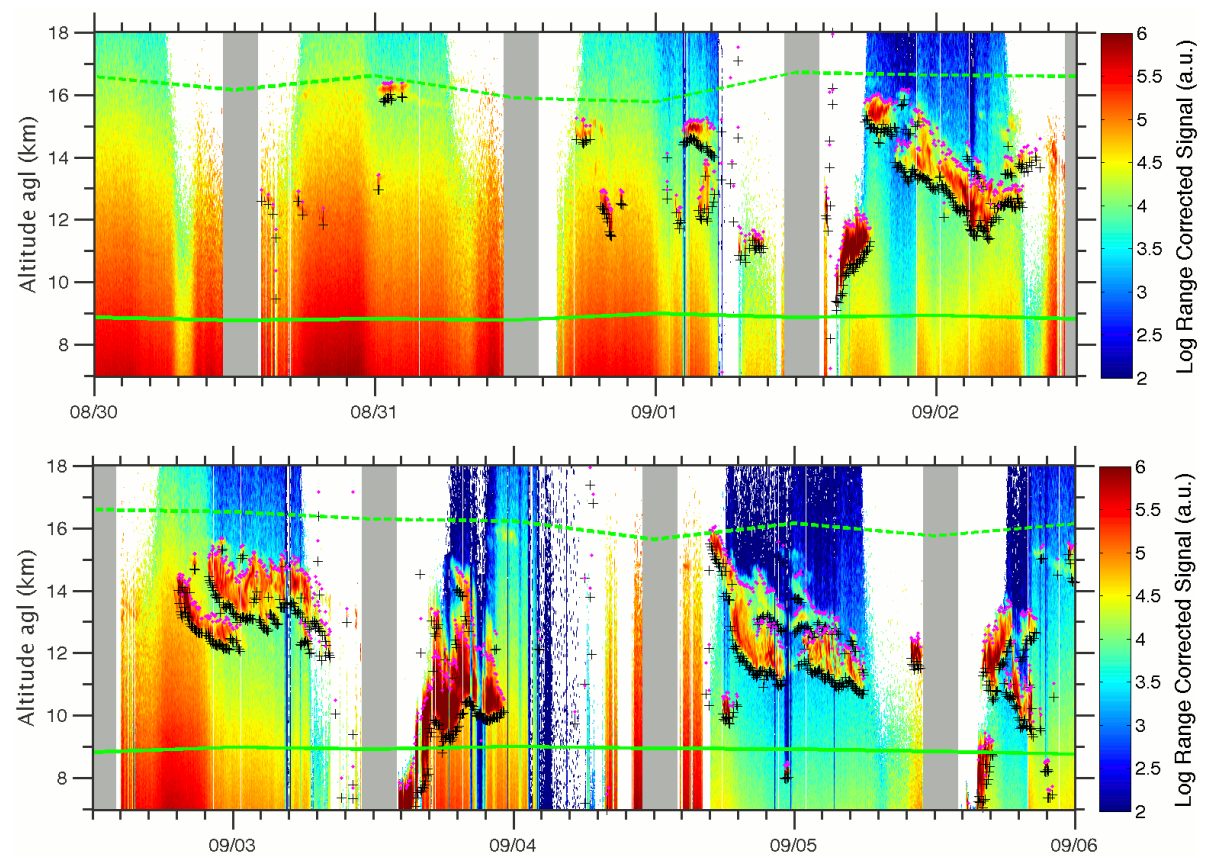

Figure 18. Logarithm of range corrected signal above $7 \mathrm{~km}$ is shown from 30 August to 6 September 2011 divided into two panels for depicting the high clouds. Cloud base (+, black) and top (o, magenta) detected by our algorithm are indicated with markers. Full and dashed green lines indicate the $-25^{\circ} \mathrm{C}$ and trotopause heights calculated from the radiosondes. Gray regions correspond to local solar.

facility has the potential to significantly improve the knowledge of the aerosol vertical distribution over Amazonia by performing multi-year long observations.

The instrument was thoroughly described and characterized. The delay of the analog and the dead time of the photon count channels were obtained experimentally. In the first case, a $0.475 \mu$ s was found corresponding to a 10-bin displacement. For the pulse pile up effects, a dead time $4.14 \pm 0.11 \mathrm{~ns}$ and $3.98 \pm 0.10 \mathrm{~ns}$ were measured for the first two channels, in agreement with the manufacturer specification. Therefore, the analysis algorithm automatically desaturates the three photon count channels assuming a nonparalyzable system with $\tau=4 \mathrm{~ns}$, and correct the analog channels for the time delay. The overlap between the laser beam and the telescope field of view was experimentally determined using the method of Wandinger and Ansman (2002). For the period before 1 August 2012, when the system used a narrow field stop, a full overlap was found at $3 \mathrm{~km}$ and its contribution to the particle extinction was found to be important below $1.5 \mathrm{~km}$. For the period with the wide field stop, these were $1.8 \mathrm{~km}$ and $1 \mathrm{~km}$, respectively. Widening the field stop allowed reducing the overlap correction uncertainty to the extinction coefficient from 88 to $36 \mathrm{Mm}^{-1} \mathrm{sr}^{-1}$ at $750 \mathrm{~m}$. Ten radiosondes were launched from the lidar site and compared to simultaneous measurements at the operational sounding site at the Manaus military airport. Differences in molecules number concentration were found to be less than $1 \%$, hence the operational soundings are used for our routine analysis.

A week of lidar measurements during the biomass burning season of 2011 were analyzed and compared with measurements from a co-located AERONET sun photometer as a mean to assess the overall system capability and performance. The period chosen was from 30 August to 6 September 2011 when an intensive campaign for calibration of the water vapor channel of the UV Raman lidar was conducted (to be discussed in an upcoming publication). Particle lidar ratios obtained during nighttime with the use of the Raman channel were between 50 and $65 \mathrm{sr}$ during the whole week, compatible with values found by previous measurements of biomass burning aerosols in the region (Baars et al., 2012). A comparison of the elastic $\left(L_{\mathrm{p}}=55 \mathrm{sr}\right)$ and Raman aerosol optical depth for each $1 \mathrm{~min}$ cloud-free nighttime profile during that week showed no systematic differences, thus allowing us to use the elastic method to compare lidar and AERONET measurements during day time. Lidar data was averaged in a $30 \mathrm{~min}$ window around the AERONET measurements, and again no systematic differences were found. The RMSE for the AOD was 0.06 with a $R^{2}=0.75$, small compared to range of observed AOD values 0.1 to 0.75 and to the total AERONET uncertainty that is about 0.02 (Holben et al., 1998). To identify the source of these particles, a backtrajectory analysis was performed using the Hysplit model from NOAA and fire detection maps from INPE. An ensemble of backtrajectories shows about half coming from 
the ocean and half from the fire spots region. As marine aerosols have lidar ratios of about $30 \mathrm{sr}$ and are washed out much more easily than BBA, we concluded that the observed particles were originated from biomass burning. Moreover, as the measured lidar ratio was rather constant even for low aerosol loadings, we also concluded that the mixture of clean air into the polluted air masses diluted the smoke plumes, therefore explaining the alternation of low $(\sim 0.1)$ and high $(\sim 0.7)$ AOD values with constant $L_{\mathrm{p}}$.

A cloud detection algorithm initially developed by Barja (2002) was improved and applied to data from that same week to detect cirrus clouds. A visual inspection of the range corrected signal and the algorithm output for the cloud base, top and height of maximum backscatter shows a very good agreement. During this period, cirrus clouds were present in $60 \%$ of our measurements in agreement with previous results (Wang and Sassen, 2001), but with high day-to-day variability (occurrence frequency varied from 15 to $83 \%$ ). Average base and top heights were 11.5 and $13.4 \mathrm{~km}$, respectively, and maximum backscatter at $12.8 \mathrm{~km}$. Most of the time, three layers of cirrus clouds were found.

Acknowledgements. We would like to acknowledge the financial support from FAPESP Research Program on Global Climate Change under research grants 2008/58100-1, 2009/15235-8, 2011/50170-4, 2012/14437-9 and 2012/16100-1. We were also supported by the Instituto Nacional de Ciência e Tecnologia (INCT) - Mudanças Climáticas and CNPq grants 477575/20080, 475735/2012-9 and 457843/2013-6. We are grateful to Mr. Fernando Morais for operation of the AERONET station at Manaus. We thank Alcides C. Ribeiro, Ana L. Loureiro, Fábio de Oliveira Jorge and Simara Morais for technical and logistical support. Operation of the instruments at the experimental site would not have been possible without the institutional support from EMBRAPA and INPA (Instituto Nacional de Pesquisas da Amazonia) LBA Central Office in Manaus. Special thanks to Birgit Heese from the Leibniz-Institut für Troposphärenforschung for providing data evaluation software on top of which we developed part of our analysis routines.

Edited by: U. Wandinger

\section{References}

Adams, D. K., Fernandes, R. M. S., Kursinski, E. R., Maia, J. M., Sapucci, L. F., Machado, L. A. T., Vitorello, I., Monico, J. F. G., Holub, K. L., Gutman, S. I., Filizola, N., and Bennett, R. A.: A dense GNSS meteorological network for observing deep convection in the Amazon, Atmos. Sci. Lett., 12, 207-212, doi:10.1002/asl.312, 2011.

Andreae, M. O., Browell, E. V., Garstang, M., Gregory, G. L., Harriss, R. C., Hill, G. F., Jacob, D. J., Pereira, M. C., Sachse, G. W., Setzer, A. W., Dias, P. L. S., Talbot, R. W., Torres, A. L., and Wofsy, S. C.: Biomass-burning emissions and associated haze layers over Amazonia, J. Geophys. Res., 93, 1509-1527, doi:10.1029/JD093iD02p01509, 1988.
Andreae, M. O., Artaxo, P., Fischer, H., Freitas, S. R., Grégoire, J.-M., Hansel, A., Hoor, P., Kormann, R., Krejci, R., Lange, L., Lelieveld, J., Lindinger, W., Longo, K., Peters, W., de Reus, M., Scheeren, B., Silva Dias, M. A. F., Ström, J., van Velthoven, P. F. J., and Williams, J.: Transport of biomass burning smoke to the upper troposphere by deep convection in the equatorial region, Geophys. Res. Lett., 28, 951-954, doi:10.1029/2000GL012391, 2001.

Andreae, M. O., Rosenfeld, D., Artaxo, P., Costa, A. A., Frank, G. P., Longo, K. M., and Silva-Dias, M. A. F.: Smoking rain clouds over the Amazon, Science, 303, 1337-1342, 2004.

Ansmann, A., Wandinger, U., Riebesell, M., Weitkamp, C., and Michaelis, W.: Independent measurement of extinction and backscatter profiles in cirrus clouds by using a combined Raman elastic-backscatter lidar, Appl. Optics, 31, 7113-7131, 1992.

Artaxo, P., Rizzo, L. V., Brito, J. F., Barbosa, H. M. J., Arana, A., Sena, E. T., Cirino, G. G., Bastos, W., Martin, S. T., and Andreae, M. O.: Atmospheric aerosols in Amazonia and land use change: from natural biogenic to biomass burning conditions, Faraday Discuss., 165, 203-235, doi:10.1039/C3FD00052D, 2013.

Baars, H.: Aerosol profiling with lidar in the Amazon Basin during the wet and dry season 2008, Ph.D. thesis, IfT, Leipzig, 191 pp., 2011.

Baars, H., Ansmann, A., Althausen, D., Engelmann, R., Artaxo, P., Pauliquevis, T., and Souza, R.: Further evidence for significant smoke transport from Africa to Amazonia, Geophys. Res. Lett., 38, L20802, doi:10.1029/2011GL049200, 2011.

Baars, H., Ansmann, A., Althausen, D., Engelmann, R., Heese, B., Müller, D., Artaxo, P., Paixao, M., Pauliquevis, T., and Souza, R.: Aerosol profiling with lidar in the Amazon Basin during the wet and dry season, J. Geophys. Res., 117, D21201, doi:10.1029/2012JD018338, 2012.

Barja, B.: Tropical Cirrus Clouds Measurements at Camagüey, Cuba, in: Lidar Remote Sensing in Atmospheric and Earth Sciences, Part II, edited by: Bissonnette, L., Roy, G., and Valle, G., 21st International Laser Radar Conference, 673-675, 2002.

Bates, D. R.: Rayleigh Scattering by Air, Planet. Space Sci., 32, 785-790, 1984.

Bevan, S. L., North, P. R. J., Grey, W. M. F., Los, S. O., and Plummer, S. E.: Impact of atmospheric aerosol from biomass burning on Amazon dry-season drought, J. Geophys. Res., 114, D09204, doi:10.1029/2008JD011112, 2009.

Bodhaine, B. A., Wood, N. B., Dutton, E. G., and Slusser, J. R.: On Rayleigh Optical Depth Calculations, J. Atmos. Ocean. Tech., 16, 1854-1861, doi:10.1175/15200426(1999)016<1854:ORODC>2.0.CO;2, 1999.

Böosenberg, J.: Ground-based differential absorption lidar for water vapor and temperature profiling: methodology, Appl. Optics, 37, 3845-3860, 1998.

Boucher, O., Randall, D., Artaxo, P., Bretherton, C., Feingold, G., Forster, P., Kerminen, V.-M., Kondo, Y., Liao, H., Lohmann, U., Rasch, P., Satheesh, S. K., Sherwood, S., Stevens, B., and Zhang, X. Y.: Climate Change 2013: The Physical Science Basis. Contribution of Working Group I to the Fifth Assessment Report of the Intergovernmental Panel on Climate Change, chap. Clouds and Aerosols, Cambridge University Press, Cambridge, United Kingdom and New York, NY, USA, 2013.

Bucholtz, A.: Rayleigh-scattering calculations for the terrestrial atmosphere, Appl. Optics, 34, 2765-2773, 1995. 
Butt, N., de Oliveira, P. A., and Costa, M. H.: Evidence that deforestation affects the onset of the rainy season in Rondonia, J. Geophys. Res., 116, 2-9, doi:10.1029/2010JD015174, 2011.

Chand, D., Guyon, P., Artaxo, P., Schmid, O., Frank, G. P., Rizzo, L. V., Mayol-Bracero, O. L., Gatti, L. V., and Andreae, M. O.: Optical and physical properties of aerosols in the boundary layer and free troposphere over the Amazon Basin during the biomass burning season, Atmos. Chem. Phys., 6, 2911-2925, doi:10.5194/acp-6-2911-2006, 2006.

Cirino, G. G., Souza, R. F., Adams, D. K., and Artaxo, P.: The effect of atmospheric aerosol particles and clouds on Net Ecosystem Exchange in Amazonia, Atmos. Chem. Phys. Discuss., 13, 28819-28868, doi:10.5194/acpd-13-28819-2013, 2013.

Davidson, E. A. and Artaxo, P.: Globally significant changes in biological processes of the Amazon Basin: Results of the Largescale Biosphere-Atmosphere Experiment, Glob. Change Biol., 10, 519-529, doi:10.1111/j.1529-8817.2003.00779.x, 2004.

Draxler, R. and Hess, G.: An overview of the HYSPLIT 4 modeling system of trajectories, dispersion, and deposition, Aust. Meteor. Mag., 47, 295-308, 1998.

Feingold, G.: First measurements of the Twomey indirect effect using ground-based remote sensors, Geophys. Res. Lett., 30, 1287, doi:10.1029/2002GL016633, 2003.

Fernald, F. G.: Analysis of atmospheric lidar observations: some comments, Appl. Optics, 23, 652-653, 1984.

Formenti, P., Andreae, M. O., Lange, L., Roberts, G., Cafmeyer, J., Rajta, I., Maenhaut, W., Holben, B. N., Artaxo, P., and Lelieveld, J.: Saharan dust in Brazil and Suriname during the Large-Scale Biosphere-Atmosphere Experiment in Amazonia (LBA) - Cooperative LBA Regional Experiment (CLAIRE) in March 1998, J. Geophys. Res., 106, 14919-14934, doi:10.1029/2000JD900827, 2001.

Forster, P., Ramaswamy, V., Artaxo, P., Berntsen, T., Betts, R., Fahey, D., Haywood, J., Lean, J., Lowe, D., Myhre, G., Nganga, J., Prinn, R., Raga, G., Schulz, M., and Van Dorland, R.: Climate Change 2007: The Physical Science Basis. Contribution of Working Group I to the Fourth Assessment Report of the Intergovernmental Panel on Climate Change, chap. Changes in Atmospheric Constituents and in Radiative Forcing, Cambridge University Press, Cambridge, United Kingdom and New York, NY, USA, 2007.

Freud, E., Rosenfeld, D., Andreae, M. O., Costa, A. A., and Artaxo, P.: Robust relations between $\mathrm{CCN}$ and the vertical evolution of cloud drop size distribution in deep convective clouds, Atmos. Chem. Phys., 8, 1661-1675, doi:10.5194/acp-8-1661-2008, 2008.

Goldfarb, L., Keckhut, P., Chanin, M.-L., and Hauchecorne, A.: Cirrus climatological results from lidar measurements at OHP (44 N. $6^{\circ}$ E), Geophys. Res. Lett., 28, 1687-1690, 2001.

Guyon, P., Frank, G. P., Welling, M., Chand, D., Artaxo, P., Rizzo, L., Nishioka, G., Kolle, O., Fritsch, H., Silva Dias, M. A. F, Gatti, L. V., Cordova, A. M., and Andreae, M. O.: Airborne measurements of trace gas and aerosol particle emissions from biomass burning in Amazonia, Atmos. Chem. Phys., 5, 2989 3002, doi:10.5194/acp-5-2989-2005, 2005.

Harriss, R. C., Wofsy, S. C., Garstang, M., Browell, E. V., Molion, L. C. B., McNeal, R. J., Hoell, J. M., Bendura, R. J., Beck, S. M., Navarro, R. L., Riley, J. T., and Snell, R. L.: The Amazon Bound- ary Layer Experiment (ABLE 2A): dry season 1985, J. Geophys. Res., 93, 1351-1360, doi:10.1029/JD093iD02p01351, 1988.

Holben, B., Eck, T., Slutsker, I., Tanré, D., Buis, J., Setzer, A., Vermote, E., Reagan, J., Kaufman, Y., Nakajima, T., Lavenu, F., Jankowiak, I., and Smirnov, A.: AERONET - A Federated Instrument Network and Data Archive for Aerosol Characterization, Remote Sens. Environ., 66, 1-16, doi:10.1016/S00344257(98)00031-5, 1998.

Immler, F. and Schrems, O.: Determination of tropical cirrus properties by simultaneous lidar and radiosondemeasurements, Geophys. Res. Lett., 29, 2090, doi:10.1029/2002GL015076, 2002.

Kaufman, Y. J., Hobbs, P. V., Kirchhoff, V. W. J. H., Artaxo, P., Remer, L. A., Holben, B. N., King, M. D., Ward, D. E., Prins, E. M., Longo, K. M., Mattos, L. F., Nobre, C. A., Spinhirne, J. D., Ji, Q., Thompson, A. M., Gleason, J. F., Christopher, S. A., and Tsay, S.-C.: Smoke, Clouds, and Radiation-Brazil (SCAR-B) experiment, J. Geophys. Res., 103, 31783-31808, doi:10.1029/98JD02281, 1998.

Kaufman, Y. J., Koren, I., Remer, L. A., Tanré, D., Ginoux, P., and Fan, S.: Dust transport and deposition observed from the Terra-Moderate Resolution Imaging Spectroradiometer (MODIS) spacecraft over the Atlantic Ocean, J. Geophys. Res., 110, D10S12, doi:10.1029/2003JD004436, 2005.

Klett, J. D.: Lidar inversion with variable backscatter/extinction ratios, Appl. Optics, 24, 1638-1643, 1985.

Knoll, G. F.: Radiation Detection and Measurement, John Wiley \& Sons Inc., United State of America, 4th Edn., 830 pp., 2010.

Koren, I., Altaratz, O., Remer, L. A., Feingold, G., Martins, J. V., and Heiblum, R. H.: Aerosol-induced intensification of rain from the tropics to mid-latitudes, Nat. Geosci., 5, 118-122, doi:10.1038/ngeo1364, 2012.

Krejci, R., Ström, J., de Reus, M., Hoor, P., Williams, J., Fischer, H., and Hansson, H.-C.: Evolution of aerosol properties over the rain forest in Surinam, South America, observed from aircraft during the LBA-CLAIRE 98 experiment, J. Geophys. Res., 108, 4561, doi:10.1029/2001JD001375, 2003.

Kuhn, U., Ganzeveld, L., Thielmann, A., Dindorf, T., Schebeske, G., Welling, M., Sciare, J., Roberts, G., Meixner, F. X., Kesselmeier, J., Lelieveld, J., Kolle, O., Ciccioli, P., Lloyd, J., Trentmann, J., Artaxo, P., and Andreae, M. O.: Impact of Manaus City on the Amazon Green Ocean atmosphere: ozone production, precursor sensitivity and aerosol load, Atmos. Chem. Phys., 10, 9251-9282, doi:10.5194/acp-10-9251-2010, 2010.

Kulmala, M., Asmi, A., Lappalainen, H. K., Baltensperger, U., Brenguier, J.-L., Facchini, M. C., Hansson, H.-C., Hov, Ø., O’Dowd, C. D., Pöschl, U., Wiedensohler, A., Boers, R., Boucher, O., de Leeuw, G., Denier van der Gon, H. A. C., Feichter, J., Krejci, R., Laj, P., Lihavainen, H., Lohmann, U., McFiggans, G., Mentel, T., Pilinis, C., Riipinen, I., Schulz, M., Stohl, A., Swietlicki, E., Vignati, E., Alves, C., Amann, M., Ammann, M., Arabas, S., Artaxo, P., Baars, H., Beddows, D. C. S., Bergström, R., Beukes, J. P., Bilde, M., Burkhart, J. F., Canonaco, F., Clegg, S. L., Coe, H., Crumeyrolle, S., D’Anna, B., Decesari, S., Gilardoni, S., Fischer, M., Fjaeraa, A. M., Fountoukis, C., George, C., Gomes, L., Halloran, P., Hamburger, T., Harrison, R. M., Herrmann, H., Hoffmann, T., Hoose, C., Hu, M., Hyvärinen, A., Hõrrak, U., Iinuma, Y., Iversen, T., Josipovic, M., Kanakidou, M., Kiendler-Scharr, A., Kirkevåg, A., Kiss, G., Klimont, Z., Kolmonen, P., Komppula, M., Kristjánsson, J.-E., 
Laakso, L., Laaksonen, A., Labonnote, L., Lanz, V. A., Lehtinen, K. E. J., Rizzo, L. V., Makkonen, R., Manninen, H. E., McMeeking, G., Merikanto, J., Minikin, A., Mirme, S., Morgan, W. T., Nemitz, E., O’Donnell, D., Panwar, T. S., Pawlowska, H., Petzold, A., Pienaar, J. J., Pio, C., Plass-Duelmer, C., Prévôt, A. S. H., Pryor, S., Reddington, C. L., Roberts, G., Rosenfeld, D., Schwarz, J., Seland, Ø., Sellegri, K., Shen, X. J., Shiraiwa, M., Siebert, H., Sierau, B., Simpson, D., Sun, J. Y., Topping, D., Tunved, P., Vaattovaara, P., Vakkari, V., Veefkind, J. P., Visschedijk, A., Vuollekoski, H., Vuolo, R., Wehner, B., Wildt, J., Woodward, S., Worsnop, D. R., van Zadelhoff, G.-J., Zardini, A. A., Zhang, K., van Zyl, P. G., Kerminen, V.-M., S Carslaw, K., and Pandis, S. N.: General overview: European Integrated project on Aerosol Cloud Climate and Air Quality interactions (EUCAARI) - integrating aerosol research from nano to global scales, Atmos. Chem. Phys., 11, 13061-13143, doi:10.5194/acp11-13061-2011, 2011.

Machado, L. A. T., Laurent, H., and Lima, A. A.: Diurnal march of the convection observed during TRMM-WETAMC/LBA, J. Geophys. Res., 107, 8064, doi:10.1029/2001JD000338, 2002.

Machado, L. A. T., Dias, M. A. F. S., Morales, C., Fisch, G., Vila, D., Albrecht, R., Goodman, S. J., Calheiros, A., Biscaro, T., Kummerow, C., Cohen, J., Fitzjarrald, D., Nascimento, E., Sakamoto, M., Cunningham, C., Chaboureau, J.-P., Petersen, W. A., Adams, D., Baldini, L., Angelis, C. F., Sapucci, L. F., Salio, P., Barbosa, H. M. J., Landulfo, E., Souza, R. F., Blakeslee, R. J., Bailey, J., Freitas, S., Lima, W. F. A., and Tokay, A.: The CHUVA Project - how does convection vary across the Brazil?, B. Am. Meteorol. Soc., online first, doi:10.1175/BAMS-D-1300084.1, 2014.

Martin, S. T., Andreae, M. O., Althausen, D., Artaxo, P., Baars, H., Borrmann, S., Chen, Q., Farmer, D. K., Guenther, A., Gunthe, S. S., Jimenez, J. L., Karl, T., Longo, K., Manzi, A., Müller, T., Pauliquevis, T., Petters, M. D., Prenni, A. J., Pöschl, U., Rizzo, L. V., Schneider, J., Smith, J. N., Swietlicki, E., Tota, J., Wang, J., Wiedensohler, A., and Zorn, S. R.: An overview of the Amazonian Aerosol Characterization Experiment 2008 (AMAZE08), Atmos. Chem. Phys., 10, 11415-11438, doi:10.5194/acp10-11415-2010, 2010.

Matthias, V., Böckmann, C., Freudenthaler, V., Pappalardo, G., Bösenberg, J., Amiridis, V., Amodeo, A., Ansmannand, A., Balis, D., Bosellia, A., Chaykovski, A., Chourdakis, G., Comeron, A., Delaval, A., De Tomasi, F., Eixmann, R., Frioud, M., Hagard, A., Iarlori, M., Komguem, L., Kreipl, S., Larcheveque, G., Linne, H., Matthey, R., Mattis, I., Papavannis, A., Pelon, J., Perrone, R. M., Persson, R., Resendes, D. P., Rizi, V., Rocadenbosch, F., Rodriguez, J. A., Sauvage, L., Schneider, J., Schumacher, R., Shcherbakov, V., Simeonov, V., Wandinger, U., Wang, X., Wiegner, M., and Zerefos, C.: Lidar intercomparisons on algorithm and system level in the frame of EARLINET, Tech. Rep. 337, Max-Planck-Institut für Meteorologie, Hamburg, 2002.

McCartney, E. J.: Optics Of the atmosphere: scattering by molecules and particles, John Wiley, New York, 1976.

Newsom, R. K., Turner, D. D., Mielke, B., Clayton, M. F., Ferrare, R., and Sivaraman, C.: Simultaneous analog and photon counting detection for Raman lidar, Appl. Optics, 48, 3903-3914, 2009.
Oliveira, P. H. F., Artaxo, P., Pires, C., de Lucca, S., Procópio, A., Holben, B., Schafer, J., Cardoso, L. F., Wofsy, S. C., and Rocha, H. R.: The effects of biomass burning aerosols and clouds on the $\mathrm{CO}_{2}$ flux in Amazonia, Tellus B, 59, 338-349, doi:10.1111/j.1600-0889.2007.00270.x, 2007.

Peck, E. R. and Reeder, K.: Dispersion of air, J. Opt. Soc. Am., 62, 958-962, 1972.

Pereira, E. B., Setzer, A. W., Gerab, F., Artaxo, P. E., Pereira, M. C., and Monroe, G.: Airborne measurements of aerosols from burning biomass in Brazil related to the TRACE A experiment, J. Geophys. Res., 101, 23983-23992, doi:10.1029/96JD00098, 1996.

Reid, J. S., Hobbs, P. V., Ferek, R. J., Blake, D. R., Martins, J. V., Dunlap, M. R., and Liousse, C.: Physical, chemical, and optical properties of regional hazes dominated by smoke in Brazil, J. Geophys. Res., 103, 32059-32080, doi:10.1029/98JD00458, 1998.

Remer, L. A., Kaufman, Y. J., Tanré, D., Mattoo, S., Chu, D. A., Martins, J. V., Li, R.-R., Ichoku, C., Levy, R. C., Kleidman, R. G., Eck, T. F., Vermote, E., and Holben, B. N.: The MODIS Aerosol Algorithm, Products, and Validation, J. Atmos. Sci., 62, 947-973, doi:10.1175/JAS3385.1, 2005.

Schafer, J. S., Eck, T. F., Holben, B. N., Artaxo, P., and Duarte, A. F.: Characterization of the optical properties of atmospheric aerosols in Amazônia from long-term AERONET monitoring (1993-1995 and 1999-2006), J. Geophys. Res., 113, 1-16, doi:10.1029/2007JD009319, 2008.

Talbot, R. W., Andreae, M. O., Berresheim, H., Artaxo, P., Garstang, M., Harriss, R. C., Beecher, K. M., and Li, S. M.: Aerosol chemistry during the wet season in central Amazonia: The influence of long-range transport, J. Geophys. Res., 95, 16955-16969, doi:10.1029/JD095iD10p16955, 1990.

Theopold, F. and Bosenberg, J.: Evaluation of DIAL measurements in the presence of signal noise, in: Prof. of the 14th International Laser Radar Conference, 209-211, 1988.

Wandinger, U.: Multiple-scattering influence on extinction and backscatter-coefficient measurement with Raman and high-spectral-resolution lidars, Appl. Optics, 37, 417-427, doi:10.1364/AO.37.000417, 1998.

Wandinger, U. and Ansman, A.: Experimental determination of the lidar overlap profile with Raman lidar, Appl. Optics, 41, 511514, 2002.

Wang, Z. and Sassen, K.: Cloud Type and Macrophysical Property Retrieval Using Multiple Remote Sensors, J. Appl. Meteorol., 40, 1665-1682, 2001.

Whiteman, D.: Application of statistical methods to the determination of slope in lidar data, Appl. Optics, 38, 3360-3369, 1999.

Whiteman, D. N., Melfi, S. H., and Ferrare, R. A.: Raman Lidar System for Measurement of Water Vapor and Aerosols in the Earth's Atmosphere, Appl. Optics, 31, 3068-3082, 1992.

Whiteman, D. N., Demoz, B., Rush, K., Schwemmer, G., Gentry, B., Di Girolamo, P., Comer, J., Veselovskii, I., Evans, K., Melfi, S. H., Wang, Z., Cadirola, M., Mielke, B., Venable, D., and Van Hove, T.: Raman Lidar Measurements during the International $\mathrm{H}_{2} \mathrm{O}$ Project. Part I: Instrumentation and Analysis Techniques, J. Atmos. Ocean. Tech., 23, 157-169, doi:10.1175/JTECH1838.1, 2006. 